\title{
Satellite derived euphotic depth in the Southern Ocean: Implications for primary production modelling
}

\author{
M.A. Soppa ${ }^{\mathrm{a}, *}$, T. Dinter ${ }^{\mathrm{a}, \mathrm{b}}$, B.B. Taylor ${ }^{\mathrm{a}}$, A. Bracher ${ }^{\mathrm{a}, \mathrm{b}}$ \\ a Alfred-Wegener-Institut Helmholtz-Zentrum für Polar- und Meeresforschung, Bussestrasse 24, D-27570, Bremerhaven, Germany \\ ${ }^{\mathrm{b}}$ Institute of Environmental Physics, University of Bremen, PO Box 330440, D-28334 Bremen, Germany
}

\section{A R T I C L E I N F O}

Article history:

Received 17 December 2012

Received in revised form 21 June 2013

Accepted 23 June 2013

Available online $\mathrm{xxxx}$

\section{Keywords:}

Euphotic zone

SeaWiFS

MODIS

Southern Ocean

Phytoplankton absorption

Ocean colour

\begin{abstract}
A B S T R A C T
The euphotic depth $\left(Z_{\text {eu }}\right)$ is a key parameter in modelling primary production (PP) using satellite ocean colour. However, evaluations of satellite $Z_{\text {eu }}$ products are scarce. The objective of this paper is to investigate existing approaches and sensors to estimate $Z_{\text {eu }}$ from satellite and to evaluate how different $Z_{\text {eu }}$ products might affect the estimation of PP in the Southern Ocean (SO). Euphotic depth was derived from MODIS and SeaWiFS products of (i) surface chlorophyll-a $\left(\mathrm{Z}_{\mathrm{eu}}-\mathrm{Chla}\right)$ and (ii) inherent optical properties $\left(\mathrm{Z}_{\mathrm{eu}}-\mathrm{IOP}\right)$. They were compared with in situ measurements of $Z_{\text {eu }}$ from different regions of the SO. Both approaches and sensors are robust to retrieve $\mathrm{Z}_{\mathrm{eu}}$, although the best results were obtained using the IOP approach and SeaWiFS data, with an average percentage of error $(E)$ of $25.43 \%$ and mean absolute error (MAE) of $0.10 \mathrm{~m}$ (log scale). Nevertheless, differences in the spatial distribution of $\mathrm{Z}_{\mathrm{eu}}$-Chla and $\mathrm{Z}_{\mathrm{eu}}$-IOP for both sensors were found as large as $30 \%$ over specific regions. These differences were also observed in PP. On average, PP based on $Z_{\mathrm{eu}}$-Chla was $8 \%$ higher than PP based on $\mathrm{Z}_{\mathrm{eu}}$-IOP, but it was up to $30 \%$ higher south of $60^{\circ} \mathrm{S}$. Satellite phytoplankton absorption coefficients $\left(a_{p h}\right)$ derived by the Quasi-Analytical Algorithm at different wavelengths were also validated and the results showed that MODIS $a_{p h}$ are generally more robust than SeaWiFS. Thus, MODIS $a_{p h}$ should be preferred in PP models based on $a_{p h}$ in the SO. Further, we reinforce the importance of investigating the spatial differences between satellite products, which might not be detected by the validation with in situ measurements due to the insufficient amount and uneven distribution of the data.
\end{abstract}

(c) 2013 Elsevier Inc. All rights reserved.

\section{Introduction}

Phytoplankton primary production (PP) is one of the key drivers regulating the ocean carbon cycle. In the Southern Ocean (SO), phytoplankton blooms develop with the retreat of sea ice in the springtime and, as a result, surface waters turn into a strong sink of $\mathrm{CO}_{2}$ (Takahashi et al., 2009). Because PP has a high spatial and temporal variability within this part of the global ocean, it is difficult to assess and monitor it with in situ measurements. Despite the efforts to accurately estimate PP from ocean colour, studies showed large differences in the SO estimates (Campbell et al., 2002; Carr et al., 2006).

A common parameter shared by different ocean colour PP models is the euphotic depth $\left(Z_{\text {eu }}\right)$. In biological terms, $Z_{\text {eu }}$ is the bottom of the euphotic zone; the part of the water column with sufficient light for supporting photosynthesis and thus PP (Falkowski \& Raven, 2007, chap. 9; Kirk, 2011, chap. 1). In physical terms, $Z_{\text {eu }}$ is the depth where the downward photosynthetic available radiation (PAR), the radiation

\footnotetext{
* Corresponding author. Tel.: + 4947148311785.

E-mail addresses: msoppa@awi.de (M.A. Soppa),dinter@iup.physik.uni-bremen.de (T. Dinter), bettina.taylor@awi.de (B.B. Taylor), astrid.bracher@awi.de (A. Bracher).
}

in the spectral range of $400-700 \mathrm{~nm}$, is reduced to $1 \%$ of its value beneath the surface (Morel \& Berthon, 1989).

In ocean colour remote sensing $Z_{\text {eu }}$ can be estimated (i) empirically from the surface chlorophyll-a concentration (Chla, $\mathrm{Z}_{\mathrm{eu}}-\mathrm{Chla}$ ) (Morel, in Lee et al., 2007) and (ii) semi-analytically from the inherent optical properties of the water (IOPs, $\mathrm{Z}_{\mathrm{eu}}-\mathrm{IOP}$ ) (Lee, Du, Arnone, Liew, \& Penta, 2005). The main difference between the two approaches is that the derivation of $Z_{\mathrm{eu}}$ from Chla assumes that the optical properties of the optically active constituents co-vary with Chla (so-called Case 1 waters). On the other hand, the IOP approach determines the vertical distribution of light from the IOPs and therefore $\mathrm{Z}_{\mathrm{eu}}$ can be retrieved in optically complex waters too, as shown by Lee et al. (2007) and Shang, Lee, and Wei (2011).

Uncertainties in $\mathrm{Z}_{\mathrm{eu}}$ estimated from satellite data in the China Sea were investigated by Shang, Lee, et al. (2011). However, to our knowledge, there is no detailed evaluation of the satellite $Z_{\mathrm{eu}}$ in the SO. A comparison of ocean colour sensor/retrievals with in situ measurements, as well as the further impact on the PP modelling is thus necessary.

In this context, the main goal of this paper is to investigate the differences in estimating $Z_{\text {eu }}$ from satellite remote sensing using different approaches and sensors in the SO. We compute $Z_{\text {eu }}$ from ocean colour products of (i) Chla and (ii) IOP and validate those using in situ 
measurements of $Z_{\mathrm{eu}}$. In addition, we compare $Z_{\mathrm{eu}}$ derived from the Moderate Resolution Imaging Spectroradiometer (MODIS) and the Sea-viewing Wide Field-of-view Sensor (SeaWiFS) sensors. The approaches and sensors are further examined in terms of the spatial distribution of $Z_{\text {eu }}$. Since phytoplankton absorption coefficient $\left(a_{p h}\right)$ data are used in the PP calculation, we also examine the uncertainties of MODIS and SeaWiFS $a_{p h}$ derived with the Quasi-Analytical Algorithm (QAA, Lee et al., 2005). Finally, we apply the absorption based primary production model (ABPM, Hirawake et al., 2011; Hirawake, Shinmyo, Fujiwara, \& Saitoh, 2012) to investigate how different $Z_{\text {eu }}$ products might affect the estimation of PP in the SO.

\section{Material and methods}

\subsection{In situ data}

A data set of in situ measurements of Chla $(\mathrm{N}=1032)$ and $\mathrm{Z}_{\mathrm{eu}}$ $(\mathrm{N}=1288)$ in the SO was built to validate the satellite measurements. The data set compiled measurements from 1997 to 2008 taken by several investigators (Fig. 1 and Table A1). The Chla data were restricted to Chla derived from High Performance Liquid Chromatography (HPLC) pigment analysis, within $12 \mathrm{~m}$ surface layer and taken within $3 \mathrm{~h}$ of the $\mathrm{Z}_{\mathrm{eu}}$ in situ measurements. An average value of Chla was calculated if two or more samples were collected within the surface layer. We used $Z_{\text {eu }}$ data provided in the databases that were calculated from in situ measurements of vertical profiles of PAR ( $N=977)$. In addition, vertical profiles of PAR were also available in the SeaBASS database (cruises are marked with * in Table A1, Appendix) and those were used to calculate $Z_{\text {eu }}(\mathrm{N}=311)$. We corrected surface measurements for wave perturbations when necessary as described in Taylor et al. (2011) and profiles not deep enough to reach the 0.01 of PAR at surface were discarded. A third data set of in situ measurements of $a_{p h}(\mathrm{~N}=465)$ was compiled to validate the $a_{p h}$ derived from satellite remote sensing reflectance $\left(R_{\mathrm{rs}}\right)$. The $a_{p h}$ data are derived from filter pad measurements taken in the years 2007, 2008, 2010 and 2012. The ANT-XXVI/3 and ANT-XXVIII/3 data were measured according to the filter pad method described in Taylor et al. (2011). Fig. 1 presents the relative frequency distribution of the $Z_{\text {eu }}$, Chla and spectrally averaged $a_{p h}$ coefficient over 400-700 nm ( $\bar{a}_{p h}$, see Section 2.4) in situ measurements that matched with SeaWiFS and MODIS data. Their relative frequency distribution by latitude and longitude is presented in the Appendix (Fig. A1).

\subsection{Satellite data}

MODIS-Aqua (R2012.0) and SeaWiFS (R2010.0) level 3 products of Chla (CHL1), PAR, $R_{\mathrm{rs}}$ were obtained at http://oceancolor.gsfc.nasa.gov/.
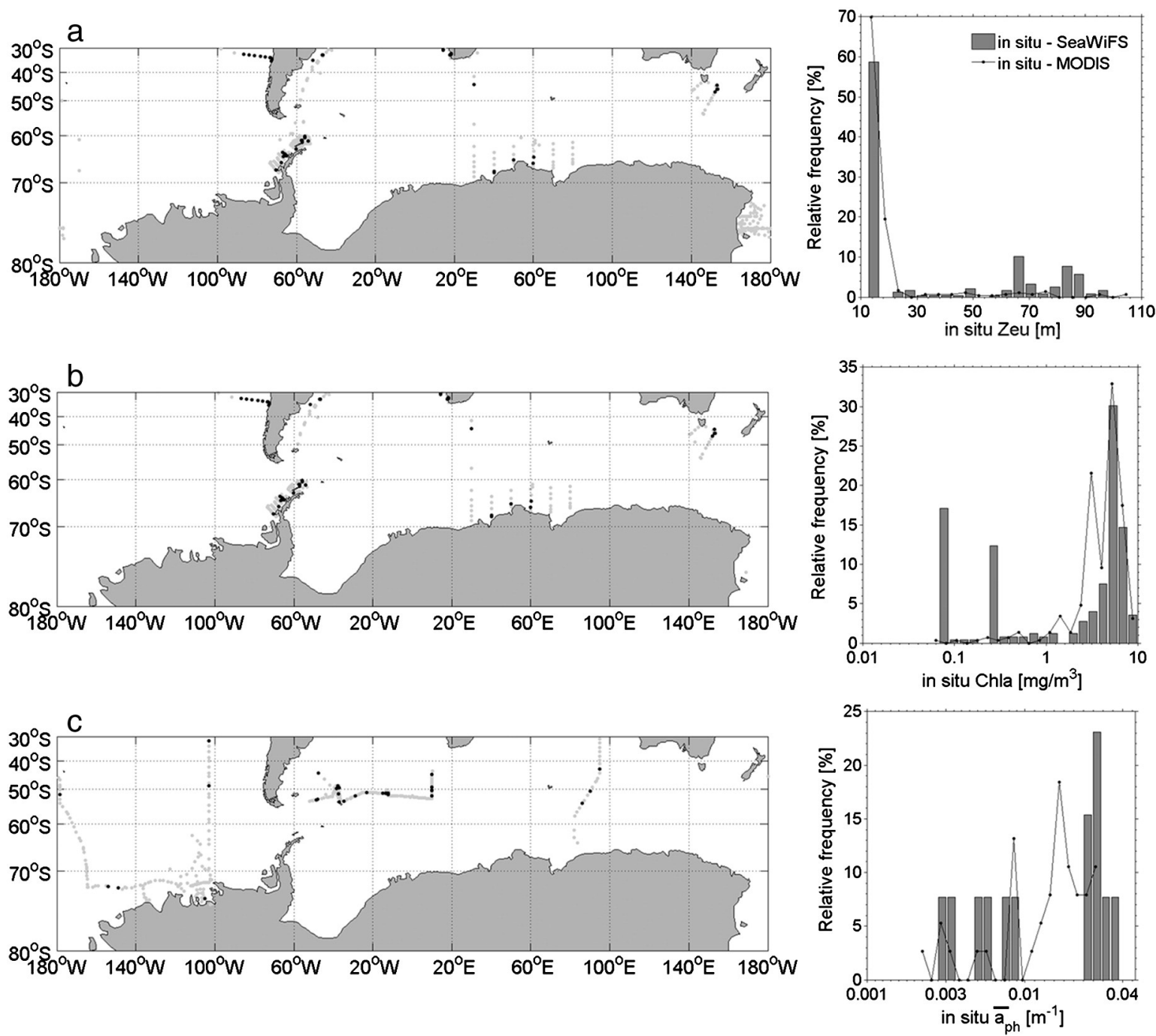

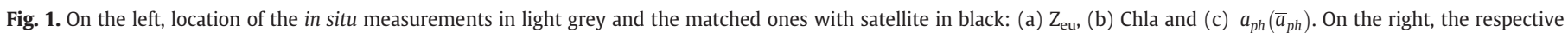
relative frequency distribution of the matched in situ measurements. 
The data are produced and distributed by the NASA Goddard Space Flight Center's Ocean Data Processing System (ODPS). The SeaWiFS data set has the longest time series; however, the data acquisition ended in December 2010. We used MODIS and SeaWiFS data at $9 \times 9 \mathrm{~km}^{2}$ spatial resolution. Satellite PAR and $a_{p h}$ derived from $R_{\mathrm{rs}}$ (see Section 2.4) were used in the PP model. For the validation with in situ measurements daily images were used; for spatial distribution analysis we used monthly data.

\section{3. $Z_{\text {eu }}$ derived from ocean colour}

Two approaches were used to derive $\mathrm{Z}_{\mathrm{eu}}$ from ocean colour products. The approaches are briefly described below:

(i) $Z_{\text {eu }}$ derived from Chla $\left(Z_{\text {eu }}-C h l a\right)$.

Based on the Case 1 waters assumption, the relationship is expressed as:

$\mathrm{Z}_{\mathrm{eu}}=34 \cdot(\text { Chla })^{-0.39}$ (Morel, in Lee et al., 2007)

Standard CHL1 data are derived using the maximum band ratio $(X)$ chlorophyll algorithms OC4v.6 (SeaWiFS) and OC3M (MODIS), defined as:

$\log ($ Chla $)=a_{0}+a_{1} X+a_{2} X^{2}+a_{3} X^{3}+a_{4} X^{4}$

where for SeaWiFS,

$X=\log \left[\frac{\max \left(R_{\mathrm{rS}}(443), R_{\mathrm{rS}}(490), R_{\mathrm{rS}}(510)\right)}{R_{\mathrm{rS}}(555)}\right]$

For MODIS two band ratios are used to replace the three band ratios in the SeaWiFS algorithm: $R_{\mathrm{rs}}(443) / R_{\mathrm{rS}}(550)$ and $R_{\mathrm{rs}}(490) /$ $R_{\mathrm{rs}}$ (550). The coefficients $a_{0}, a_{1}, a_{2}, a_{3}$ and $a_{4}$ are $0.3272,-2.9940$, $2.7218,-1.2259$ and -0.5683 for SeaWiFS (Feldman \& McClain, 2011) and $0.283,-2.753,+1.457,+0.659$ and -1.403 for MODIS (O'Reilly et al., 2000).

(ii) $Z_{\text {eu }}$ derived from the IOPs $\left(Z_{\text {eu }}-\mathrm{IOP}\right)$.

The QAA (version 5, Lee, Lubac, Werdell, \& Arnone, 2009) was applied to derive the absorption and backscattering coefficients at $490 \mathrm{~nm}$ (a490 and $\mathrm{b}_{\mathrm{b}} 490$ ) from the satellite $R_{\mathrm{rs}}$. Briefly, the QAA is an inversion algorithm that analytically derives the absorption and backscattering coefficients from the $R_{\mathrm{rs}}$. First, the total absorption coefficient was calculated at a reference wavelength $\left(\lambda_{0}, 555 \mathrm{~nm}\right.$ for SeaWiFS and $550 \mathrm{~nm}$ for MODIS) (Lee et al., 2009):

$a\left(\lambda_{0}\right)=a_{w}\left(\lambda_{0}\right)+10^{-1.146-1.366 X-0.469 X^{2}}$

where,

$$
X=\log \left[\frac{r_{\mathrm{rs}}(443)+r_{\mathrm{rs}}(490)}{r_{\mathrm{rs}}\left(\lambda_{0}\right)+5 \frac{r_{\mathrm{rs}}(667)}{r_{\mathrm{rs}}(490)} \cdot r_{\mathrm{rs}}(667)}\right]
$$

Subsequently, the calculation was propagated to the other wavelengths. The vertical attenuation coefficient of PAR $\left(K_{\mathrm{PAR}}\right)$ was then derived from a 490 and $b_{b} 490$. $Z_{\text {eu }}$ was determined as:

$\mathrm{Z}_{\mathrm{eu}}=\frac{4.605}{K_{\mathrm{PAR}}\left(Z_{\mathrm{eu}}\right)}$ (Lee et al., 2007)

Details on the algorithm and its uncertainties are presented in Lee et al. (2005), Lee, Carder, and Arnone (2006) and Lee, Arnone, Hu, Werdell, and Lubac (2010).

\subsection{Primary production model}

The net PP was calculated using the ABPM (Hirawake et al., 2011, 2012), an improved version of the Vertically Generalized Production Model (Behrenfeld \& Falkowski, 1997) for polar oceans. In the ABPM, the product of the chlorophyll- $a$ normalized maximum photosynthetic rate in the water column $\left(P_{\mathrm{opt}}^{B}, \mathrm{mg} \mathrm{C}(\mathrm{mg} \text { Chla })^{-1} \mathrm{~h}^{-1}\right)$ and Chla $\left(\mathrm{mg} \mathrm{m}^{-3}\right)$ is replaced by a linear relation of the spectrally averaged $a_{p h}$ coefficient over $400-700 \mathrm{~nm}\left(\bar{a}_{p h}, m^{-1}\right)$. This model eliminates uncertainties of the satellite Chla product and the temperature effect on the estimation of the $P_{\mathrm{opt}}^{\mathrm{B}}$ (Hirawake et al., 2011). The ABPM is expressed as:

$N P P=109.66 \cdot \bar{a}_{p h}\left(0^{-}\right)-0.02 \cdot \frac{0.66125 \cdot E_{0}}{E_{0}+4.1} \cdot Z_{\text {eu }} \cdot D_{\text {irr }}$

where $E_{0}$ is the daily integrated photosynthetic available radiation (PAR, Einsteins $\mathrm{m}^{-2}$ day $^{-1}$ ) from satellite (see Section 2.2) and $D_{\text {irr }}$ is the photoperiod $(\mathrm{h})$ calculated as described in http://orca.science. oregonstate.edu/faq01.php. The PP estimated from $\mathrm{Z}_{\mathrm{eu}}-\mathrm{Chla}$ is represented as PP- $\mathrm{Z}_{\mathrm{eu}}-$ Chla and from $\mathrm{Z}_{\mathrm{eu}}-\mathrm{IOP}$ as $\mathrm{PP}-\mathrm{Z}_{\mathrm{eu}}-\mathrm{IOP}$.

The QAA was applied to derive the $a_{p h}$ at the SeaWiFS spectral bands of 412, 443, 490, 510 and $555 \mathrm{~nm}$ and MODIS spectral bands of $412,443,488,531$ and $555 \mathrm{~nm}$. Satellite $\bar{a}_{p h}$ ph were then derived by adjusting the $a_{p h}$ integrated over the visible bands of SeaWiFS and MODIS to the in situ $\bar{a}_{p h}$ over the continuous visible range (400-700) (Hirawake et al., 2011, 2012):

$\bar{a}_{p h}\left(0^{-}\right)=\frac{a \cdot \sum_{N=1}^{4}\left[\left(a_{p h}\left(\lambda_{i+1}\right)+a_{p h}\left(\lambda_{i}\right)\right) \cdot\left(\left(\lambda_{i+1}-\lambda_{i}\right) / 2\right)\right]}{700-400}$

where $\lambda$ were the above mentioned spectral bands of SeaWiFS and MODIS. The parameter $a$ represents the slope of the regression of the satellite $\bar{a}_{p h}$ to the in situ $\bar{a}_{p h}$ and corresponded to 1.3656 for SeaWiFS and 1.5354 for MODIS.

\subsection{Validation and statistical analysis}

The MODIS and SeaWiFS match ups were obtained when the day, latitude and longitude of the in situ observation fell within the limits of $1 \times 1$ pixel window. The bias, average absolute percentage of error $(E)$, root mean square error (RMSE) and mean absolute error (MAE) were calculated to evaluate the differences between the in situ $\mathrm{Z}_{\mathrm{eu}}$ and the satellite $\mathrm{Z}_{\mathrm{eu}}$ :

$\log$ bias $=\frac{1}{N} \sum_{i=1}^{N}\left(\log \left(Y_{i}\right)-\log \left(X_{i}\right)\right)$

$E=\left(\frac{1}{N} \sum_{i=1}^{N}\left|\frac{Y_{i}-X_{i}}{X_{i}}\right|\right) \cdot 100 \%$

$\log \_$RMSE $=\sqrt{\frac{1}{N}} \sum_{i=1}^{N}\left(\log \left(Y_{i}\right)-\log \left(X_{i}\right)\right)^{2}$

$\log _{-}$MAE $=\frac{1}{N} \sum_{i=1}^{N} \mid\left(\log \left(Y_{i}\right)-\log \left(X_{i}\right) \mid\right.$

where $X$ was the in situ value, $Y$ the satellite value and $N$ is the number of matching pairs. The statistical indicators $\log$ _bias, $E$ and log_RMSE were chosen based on the GlobColour Validation Report (2007) and other literatures on satellite validation (e.g. Zibordi, Melin, \& Berthon, 2006; Shang, Lee, et al., 2011. The log_MAE was used as a statistical estimator of error for comparisons between the sensors and $a_{p h}$ at different wavelengths, since $N$ changes. Willmott and Matsuura (2005) showed that RMSE is sensitive to the square root of $N$ and MAE should be preferred instead. No outliers were removed. For reference, a 1:1 line was included in the scatterplots to show how well the satellite and in situ data agree. 
Monthly climatologies of $\mathrm{Z}_{\mathrm{eu}}$ and PP in December, January and February, were computed to investigate spatial differences. The climatology fields were calculated from monthly images for the 2003-2009 period, excluding the year of 2008 when SeaWiFS did not acquire data. For each pixel, the relative difference between the spatial fields was derived:

$\mathrm{DIFF}=\left(\frac{A-B}{B}\right) \cdot 100 \%$

where A corresponded to $\mathrm{Z}_{\mathrm{eu}}-\mathrm{Chla}, \mathrm{Z}_{\mathrm{eu}}-\mathrm{SWF}$ or PP-Z $\mathrm{Z}_{\mathrm{eu}}-\mathrm{Chla}$ and $\mathrm{B}$ to $\mathrm{Z}_{\mathrm{eu}}$-IOP, $\mathrm{Z}_{\mathrm{eu}}$-MODIS or PP- $\mathrm{Z}_{\mathrm{eu}}$-IOP. We did not compare the spatial distribution of PP between the sensors because $\bar{a}_{p h}$, PAR and Chla might introduce differences in the PP estimation.

\section{Results}

\subsection{Comparison of satellite and in situ $Z_{e u}$}

Fig. 2 presents the comparison between satellite and in situ $Z_{\text {eu. }}$. The overall statistics show that the two approaches agree well with the in situ measurements. When $\mathrm{Z}_{\mathrm{eu}}$-SWF was derived by the IOP approach, the statistics are slightly better than $\mathrm{Z}_{\mathrm{eu}}$-Chla improving the $E$ in $3.5 \%$ (Fig. 2a and b) and the regression line is close to the $1: 1$ line (dotted line). On the other hand, $\mathrm{Z}_{\mathrm{eu}}$-Chla shows better results than $\mathrm{Z}_{\mathrm{eu}}-\mathrm{IOP}$ for MODIS, reducing the $E$ in $9.5 \%$ (Fig. $3 \mathrm{c}$ and d). Differences in $\log$ _MAE indicate that $Z_{\text {eu }}$ retrieved from SeaWiFS is more accurate than MODIS. Negative biases are found for $\mathrm{Z}_{\mathrm{eu}}-\mathrm{MODIS}$ and positive biases for $\mathrm{Z}_{\mathrm{eu}}-\mathrm{SWF}$.

Compared to collocated in situ HPLC Chla data of our validation data set, the standard SeaWiFS algorithm (OC4v.6) underestimates Chla (Fig. 3). For MODIS, the OC3M algorithm leads to under- and overestimation of Chla depending on the in situ Chla. For in situ Chla $<1.5 \mathrm{mg} / \mathrm{m}^{3}$, Chla was on average underestimated, whereas for higher concentrations $\left(>1.5 \mathrm{mg} / \mathrm{m}^{3}\right)$ the retrievals were overestimating the in situ values.

\subsection{Spatial distribution of $Z_{e u}$-Chla and $Z_{e u}-I O P$}

Fig. 4 presents the spatial distribution of the climatology of $Z_{\text {eu }}$ for February, using data from 2003 to 2009. Deeper $Z_{\text {eu }}$ are associated with oligotrophic waters in the zonal band of $30^{\circ}-40^{\circ} \mathrm{S}$. Shallower $Z_{\text {eu }}$ are observed in the waters around the Antarctic continent, South America, south and west part of South Africa and between $40^{\circ}-50^{\circ} \mathrm{S}$, except for the eastern Pacific Sector. Shallower $Z_{\text {eu }}$ is related to terrigenous influence (e.g. La Plata river plume in the Patagonian Shelf region) and higher chlorophyll concentrations in upwelling regions (e.g. Benguella upwelling), polar fronts, islands (e.g. Kerguelen islands) and continental shelves (e.g. Antarctic Peninsula). The dynamic of Chla in the SO was recently investigated by Thomalla, Fauchereau, Swart, and Monteiro (2011). For comparison, the spatial distribution of $Z_{\text {eu }}$ in February 2003 is presented in the Appendix and shows that there are no major differences between monthly and climatology maps (Fig. A2). The difference
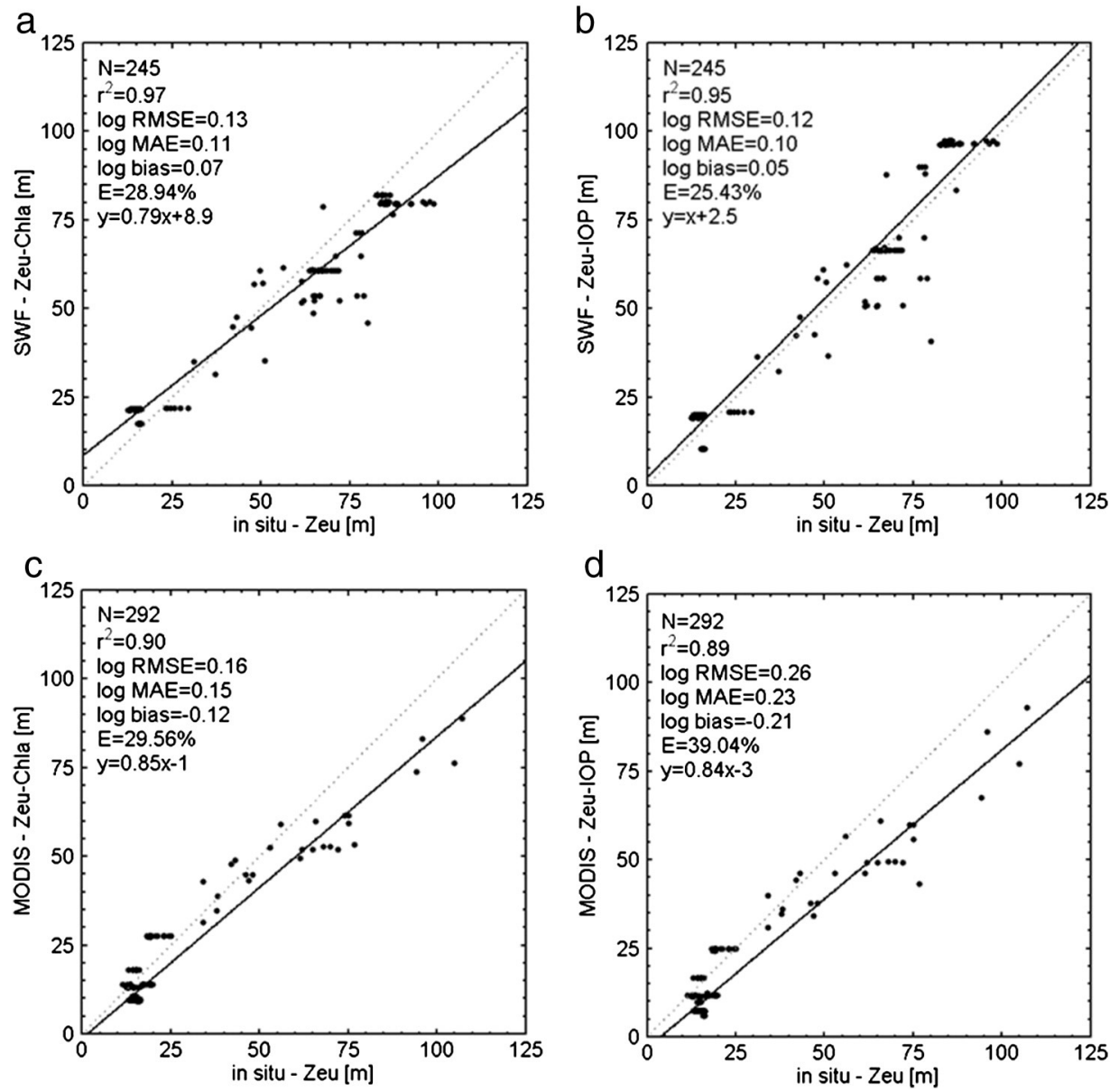

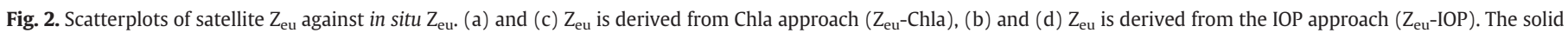
line represents the regression and the dotted line represents 1:1 line as reference. 

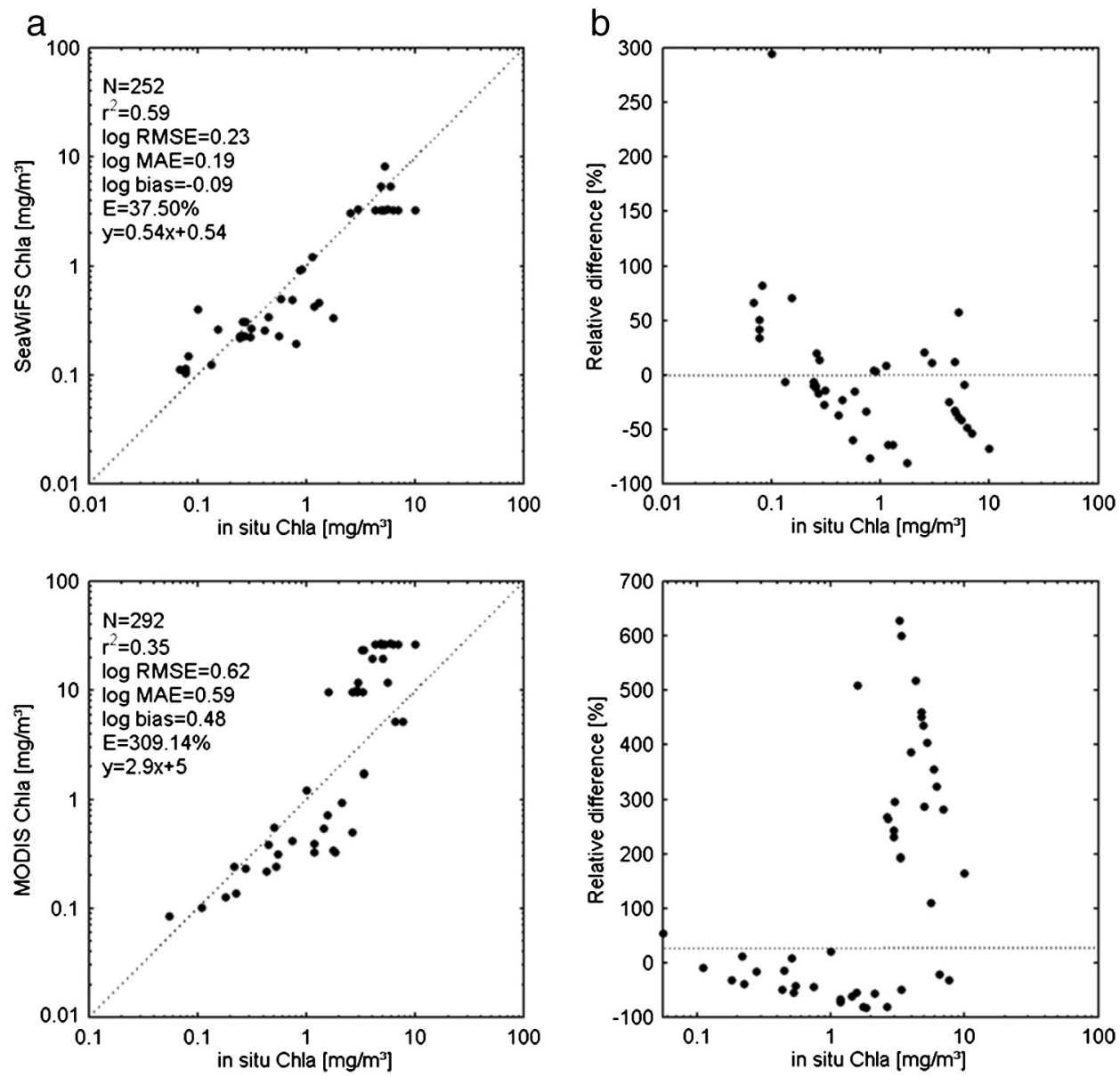

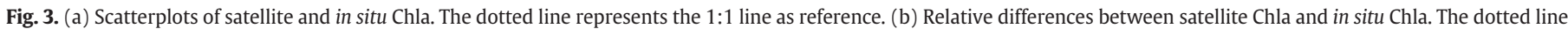
represents the zero line.

in calculating the climatology of $Z_{\mathrm{eu}}$ from daily or monthly images was small as well. For instance, the standard deviations of the difference between $\mathrm{Z}_{\mathrm{eu}}$-Chla calculated from daily data and monthly data in February 2003 are $1.22 \mathrm{~m}$ for SWF and $1.08 \mathrm{~m}$ for MODIS. For the IOP approach the values are $0.91 \mathrm{~m}$ for SeaWiFS and $0.77 \mathrm{~m}$ for MODIS.

When $\mathrm{Z}_{\mathrm{eu}}$-Chla was compared with $\mathrm{Z}_{\mathrm{eu}}-\mathrm{IOP}$, large differences were observed. While the range of $\mathrm{Z}_{\mathrm{eu}}$-Chla from SeaWiFS varies between 5.97 and $234.31 \mathrm{~m}$ (median $=65.50 \mathrm{~m}$ ), using the IOP approach this range is much narrower, from 2.5 to $150 \mathrm{~m}$ (median $=63.93 \mathrm{~m}$ ). Similar for MODIS, $Z_{\mathrm{eu}}$-Chla varies between 5.89 and $259.69 \mathrm{~m}$ (median = $65.50 \mathrm{~m}$ ) and $\mathrm{Z}_{\mathrm{eu}}$-IOP from 3.5 to $146.3 \mathrm{~m}$ (median $=62.37 \mathrm{~m}$ ). On average, for the entire region, $Z_{\mathrm{eu}}$-Chla from SeaWiFS and MODIS are 3.61 and $5.41 \%$ deeper than $Z_{\text {eu }}$-IOP. These differences followed a zonal distribution. The most notable difference was observed in the Pacific Sector within the $30^{\circ}-40^{\circ} \mathrm{S}$ zonal band, corresponding to the South Pacific subtropical gyre, where $Z_{\text {eu }}$-Chla is $\sim 20-30 \%$ deeper than $Z_{\text {eu }}-I O P$. The spatial distribution maps also pointed out differences of about $10-15 \%$ south of $60^{\circ} \mathrm{S}$, with $Z_{\mathrm{eu}}$-Chla usually deeper than $Z_{\mathrm{eu}}-\mathrm{IOP}$; especially for MODIS. Regions corresponding to deeper $\mathrm{Z}_{\mathrm{eu}}-\mathrm{IOP}$ were also presented, but they were less abundant and only about $\sim 10 \%$ deeper.

Comparing the sensors, the spatial distribution of $Z_{\mathrm{eu}}$ is similar in both approaches, with an average difference (DIFF) of -0.005 and $2.68 \%$ for $Z_{\text {eu }}-$ Chla and $Z_{\text {eu }}-$ IOP, respectively in February (Fig. 5). However, the spatial differences are larger south of $60^{\circ} \mathrm{S}$ and more evident in $\mathrm{Z}_{\mathrm{eu}}-\mathrm{IOP}$. A corresponding pattern was observed in December and
January. As to the spatial distribution of $Z_{e u}$, no major differences between monthly and climatology maps of DIFF were found (Fig. A3).

\subsection{Net primary production}

\subsubsection{Validation of SeaWiFS and MODIS derived phytoplankton absorption coefficients}

The ocean colour PP model used here is a function of $\bar{a}_{p h}$. The $\bar{a}_{p h}$ can be determined empirically through linear relations between in situ $\bar{a}_{p h}$ and satellite $a_{\mathrm{ph}}$ integrated over the visible spectral bands of SeaWiFS and MODIS. Hirawake et al. $(2011,2012)$ calculated these relationships based on $a_{p h}$ derived from ship $R_{\mathrm{rs}}$ at the MODIS and SeaWiFS spectral bands, using the QAA. However, within this study the satellite $R_{\mathrm{rs}}$ derived $a_{p h}$ were not validated due to the insufficient number of collocations between satellite and in situ data. Furthermore, to our knowledge, there is no information on the performance of the QAA to derive $a_{p h}$ from satellite $R_{\mathrm{rs}}$ in the SO. Therefore, before we investigated the PP, we briefly assessed the quality of the $a_{p h}$ derived from SeaWiFS and MODIS $R_{\mathrm{rs}}$ using the QAA with in situ $a_{p h}$. Results are presented in Table 1.

The log_MAE and $E$ of $a_{p h}-$ SWF increase for increasing wavelengths (except at $555 \mathrm{~nm}$ ) and negative biases indicate an underestimation of $a_{p h}$. Results for MODIS show similar $\log$ MAE and $E$ at 412, 443 and $488 \mathrm{~nm}$, increasing towards $555 \mathrm{~nm}$. Negative $a_{p h}$ values were retrieved at SeaWiFS bands 490, 510 and 555 and at MODIS bands 412 and $443 \mathrm{~nm}$ and lead to small but negative $\bar{a}_{p h}$. Those values were removed before the 


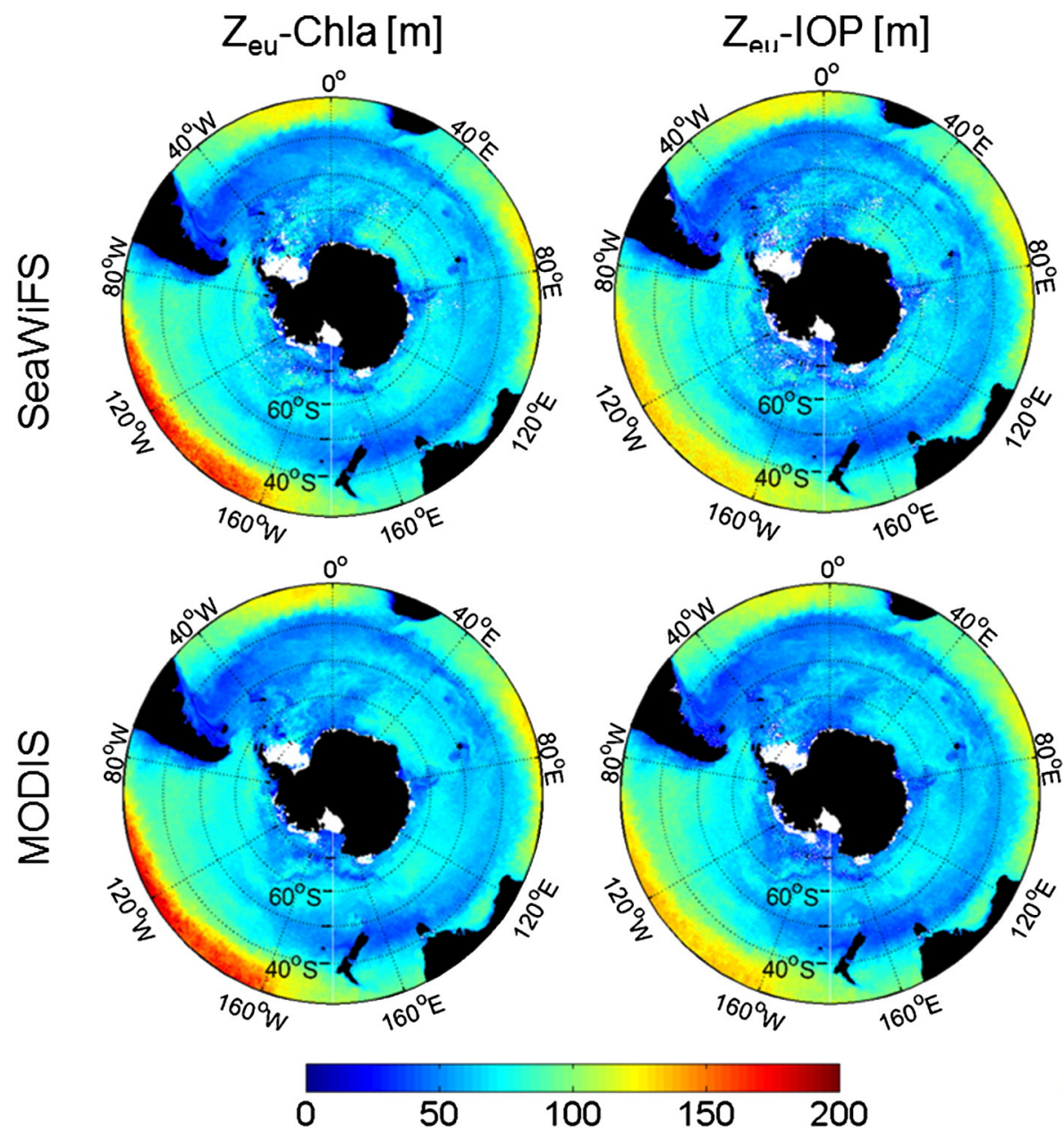

$Z_{e-11}-1 O P[\mathrm{~m}]$

150

200

Fig. 4. Spatial distribution of $Z_{\mathrm{eu}}$ in the Southern Ocean (climatology of February). The white pixels correspond to areas with no data.

calculation of the statistics presented in Table 1. Estimates of PP on pixels with negative $\bar{a}_{p h}$ were removed as well.

\subsubsection{Spatial distribution of $P P-Z_{e u}-$ Chla and $P P-Z_{e u}-I O P$}

Generally, higher PP-Z $\mathrm{Z}_{\mathrm{eu}}-\mathrm{Chla}$ than PP- $\mathrm{Z}_{\mathrm{eu}}-\mathrm{IOP}$ was observed using both sensors over the SO (Fig. 6). For SeaWiFS PP-Z $\mathrm{Z}_{\mathrm{eu}}-$ Chla was 7\% higher than PP-Z $\mathrm{Z}_{\mathrm{eu}}-\mathrm{IOP}$ and for MODIS $10.22 \%$ higher. The average of PP- $\mathrm{Z}_{\mathrm{eu}}-\mathrm{Chla}$ and PP-Z $\mathrm{eu}^{-I O P}$ was 321.18 and $283.84 \mathrm{mg} \mathrm{C} \mathrm{m}^{-2} \mathrm{~d}^{-1}$ for SeaWiFS, respectively. Using MODIS data the PP-Z ${ }_{\mathrm{eu}}-\mathrm{Chla}$ and

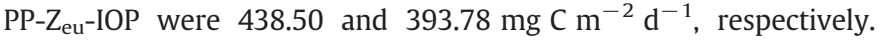
The corresponding monthly data for February 2003 are presented in the Appendix (Fig. A4). Although these differences may not be significant for studies focussing on the entire SO, for local comparisons they are relevant. For instance, in the region south of $60^{\circ} \mathrm{S}$ $\left(60^{\circ} \mathrm{S}-80^{\circ} \mathrm{S}, 120^{\circ} \mathrm{W}-160^{\circ} \mathrm{W}\right) \mathrm{PP}-\mathrm{Z}_{\mathrm{eu}}-\mathrm{Chla}$ was $~ 30 \%$ higher than $\mathrm{PP}-\mathrm{Z}_{\mathrm{eu}}-\mathrm{IOP}$.

\section{Discussion}

\subsection{Validation of Zeu and Chla}

This study investigated the differences between two approaches to derive satellite $Z_{\mathrm{eu}}$ : the first one by Morel (in Lee et al., 2007) is empirical and based on Chla and the second one by Lee et al. (2005) is semi-analytical and based on IOPs. We focussed on the Chla approach because of its simplicity, but also to investigate if the known inaccuracy of the standard satellite Chla products in the SO would impact the $\mathrm{Z}_{\mathrm{eu}}$

\section{$Z_{\text {e.11 }}$ Difference (\%)}
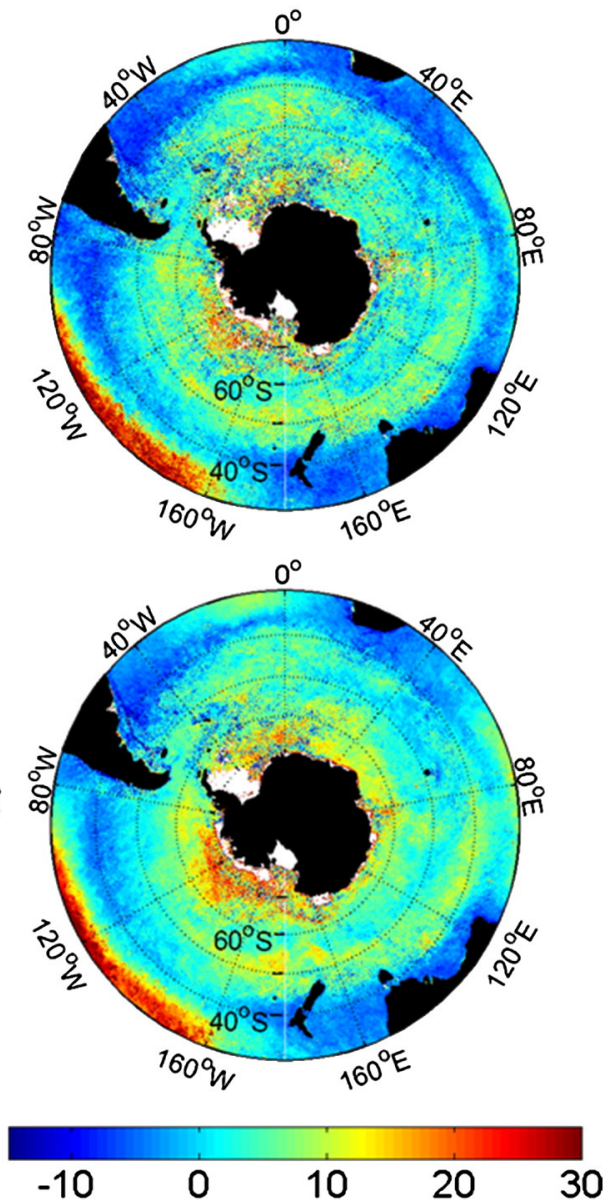
December
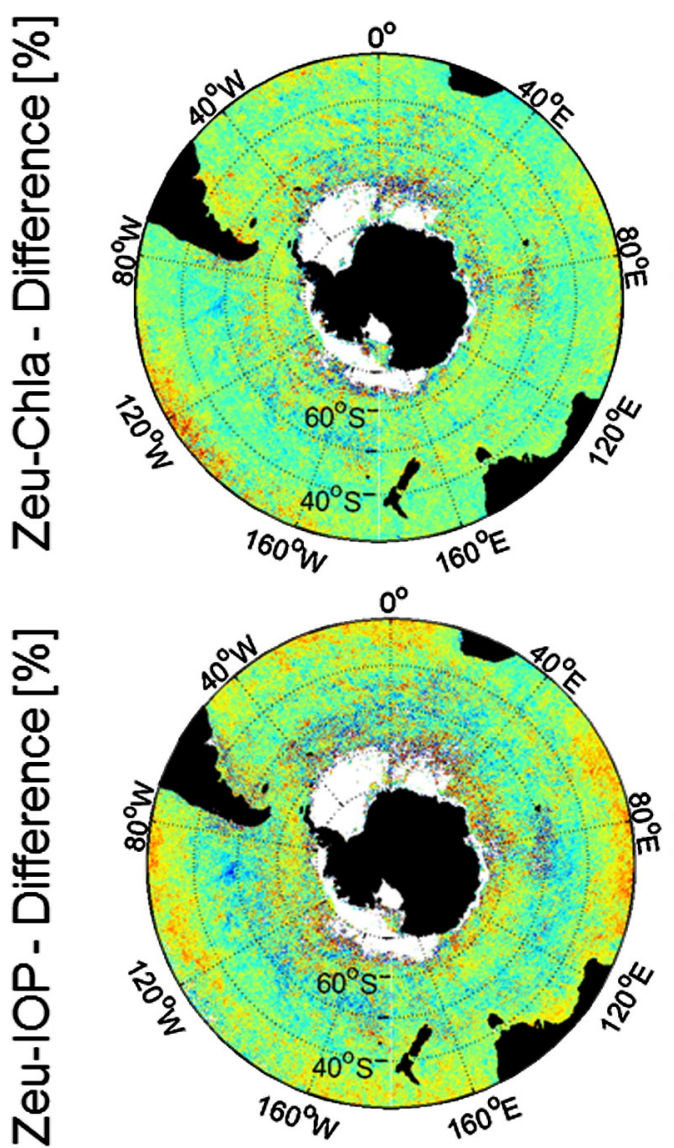

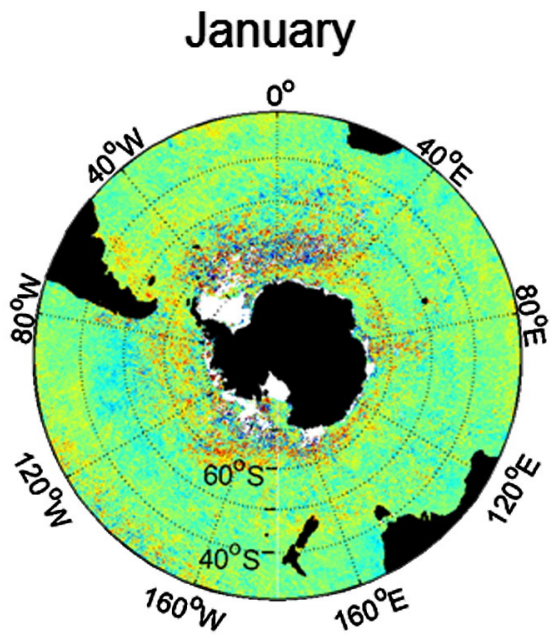

January

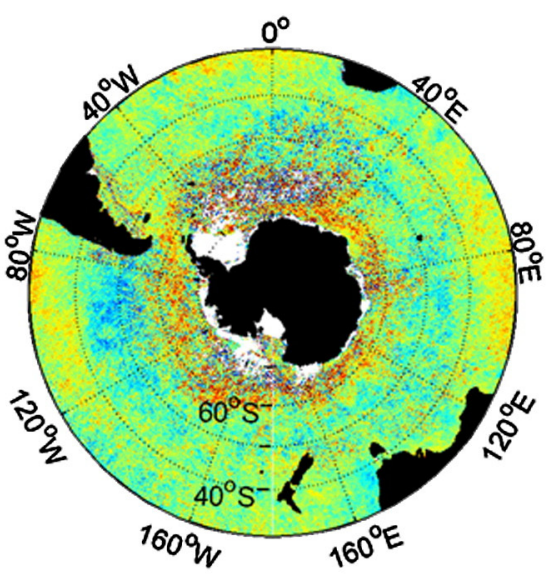

February
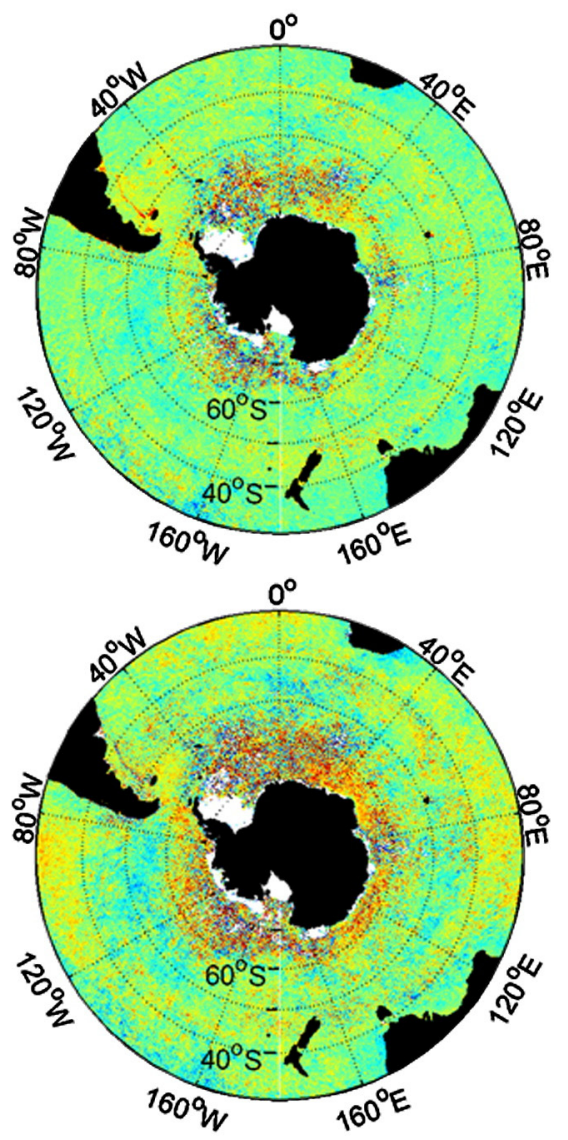

$\begin{array}{lllllll}-30 & -20 & -10 & 0 & 10 & 20 & 30\end{array}$

Fig. 5. Spatial distribution of the relative percentage of difference between SeaWiFS and MODIS. The white pixels correspond to areas with no data.

binning, as already pointed out by Mélin (2011). Differences might be caused by the granularity and coverage areas, spectral bands, orbital characteristics and equator crossing times. MODIS-Aqua crosses the equator at $\sim 13: 30 \mathrm{pm}$. For SeaWiFS the equator crossing time drifted throughout the mission, from 12:00 to 14:20, but 12:30 pm was used for the calculations. Additional sources of error in the validation analysis include the in situ measurements, as the use of different field sensors and data/sample processing.

Table 1

Statistical results of the comparison between QAA-satellite derived $a_{p h}$ and in situ $a_{p h}$.

\begin{tabular}{|c|c|c|c|c|c|c|}
\hline & & & & & & Range \\
\hline $\begin{array}{l}\text { Wavelength } \\
(\mathrm{nm})\end{array}$ & $r^{2}$ & log_MAE & log_bias & $E(\%)$ & Satellite & In situ \\
\hline \multicolumn{7}{|c|}{ SeaWiFS $(N=13)$} \\
\hline $412(\mathrm{~N}=13)$ & 0.79 & 0.21 & -0.16 & 37.55 & $0.002-0.149$ & $0.007-0.110$ \\
\hline $443(\mathrm{~N}=13)$ & 0.57 & 0.22 & -0.11 & 44.90 & $0.003-0.171$ & $0.007-0.092$ \\
\hline $490(\mathrm{~N}=12)$ & 0.23 & 0.27 & -0.03 & 75.52 & $0.008-0.119$ & $0.003-0.056$ \\
\hline $510(\mathrm{~N}=12)$ & 0.12 & 0.45 & -0.28 & 89.31 & $0.001-0.083$ & $0.001-0.054$ \\
\hline $555(\mathrm{~N}=12)$ & 0.40 & 0.35 & -0.28 & 57.01 & $0.0003-0.042$ & $0.001-0.002$ \\
\hline $\bar{a}_{p h}(\mathrm{~N}=12)$ & 0.50 & 0.22 & -0.10 & 47.40 & $0.005-0.076$ & $0.003-0.034$ \\
\hline \multicolumn{7}{|c|}{$\operatorname{MODIS}(N=38)$} \\
\hline $412(\mathrm{~N}=36)$ & 0.34 & 0.18 & -0.04 & 45.51 & $0.009-0.066$ & $0.004-0.056$ \\
\hline $443(\mathrm{~N}=36)$ & 0.33 & 0.17 & -0.005 & 48.93 & $0.011-0.079$ & $0.005-0.064$ \\
\hline $488(\mathrm{~N}=38)$ & 0.38 & 0.18 & -0.035 & 47.26 & $0.004-0.050$ & $0.003-0.047$ \\
\hline $531(\mathrm{~N}=38)$ & 0.38 & 0.22 & 0.01 & 62.21 & $0.001-0.025$ & $0.0001-0.025$ \\
\hline $555(\mathrm{~N}=38)$ & 0.21 & 0.50 & 0.50 & 406.41 & $0.009-0.025$ & $0.0004-0.014$ \\
\hline $\bar{a}_{p h}(\mathrm{~N}=36)$ & 0.44 & 0.16 & 0.06 & 53.08 & $0.006-0.038$ & $0.002-0.030$ \\
\hline
\end{tabular}

Results of the Chla validation indicate that the satellite CHL1 products from SeaWiFS are more accurate than from MODIS in the SO (Fig. 3). Our MODIS validation data set is, however, biased towards high Chla waters (Fig. 1); $95 \%$ of the in situ data had Chla $>1 \mathrm{mg} / \mathrm{m}^{3}$ where the errors are generally higher as well. In contrast, the SeaWiFS validation data set has only $65 \%$ of samples at Chla $>1 \mathrm{mg} / \mathrm{m}^{3}$. For instance, the difference in the log_MAE between MODIS and SeaWiFS for Chla $<1 \mathrm{mg} / \mathrm{m}^{3}$ is $0.02 \mathrm{mg} / \mathrm{m}^{3}\left(0.17 \mathrm{mg} / \mathrm{m}^{3}\right.$ for MODIS and $0.15 \mathrm{mg} / \mathrm{m}^{3}$ for SeaWiFS); for higher concentrations this difference increases to $0.4 \mathrm{mg} / \mathrm{m}^{3}$ $\left(0.61 \mathrm{mg} / \mathrm{m}^{3}\right.$ for MODIS and $0.21 \mathrm{mg} / \mathrm{m}^{3}$ for SeaWiFS). The observed underestimation of Chla by the operational SeaWiFS and MODIS algorithms (here only for Chla $<1.5 \mathrm{mg} / \mathrm{m}^{3}$ ) is in accordance with previous studies that used earlier algorithm versions, indicating that this issue still persists in the SO (Dierssen \& Smith, 2000; Garcia, Garcia, \& McClain, 2005; Kahru \& Mitchell, 2010; Szeto, Werdell, Moore, \& Campbell, 2011). Further, it is important to mention that we used surface Chla (see Section 2.1) instead of the weighted Chla in first optical depth. Our coincident in situ measurements of HPLC Chla profiles, $\mathrm{K}_{\mathrm{d}}$ and $\mathrm{Z}_{\mathrm{eu}}$ were all concentrated in the Antarctic Peninsula region, which represents a particular region of the SO, thus we used surface Chla values only. Moreover, we avoided the use of fluorometric data in our study and used HPLC data. Marrari, Hu, and Daly (2006) showed that the chlorophyll fluorescence of accessory pigments (e.g. chlorophyll-b) interferes in the determination of Chla by fluorometric methods in the SO.

Nevertheless, uncertainties of the satellite Chla have some but small influence on the $\mathrm{Z}_{\mathrm{eu}}$-Chla, which is in part linked to the nature of the power function that empirically relates $Z_{\mathrm{eu}}$ to Chla. One has 

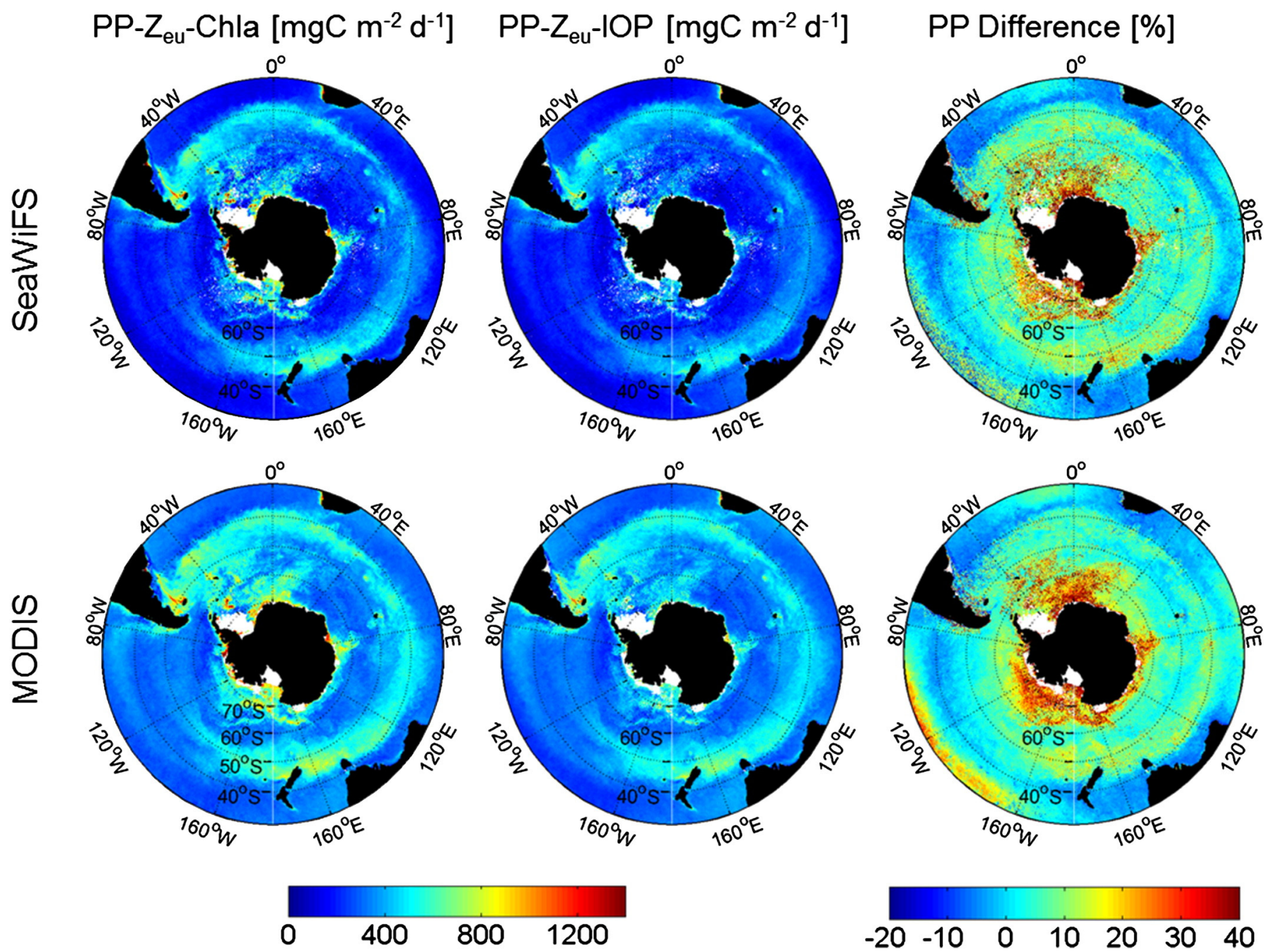

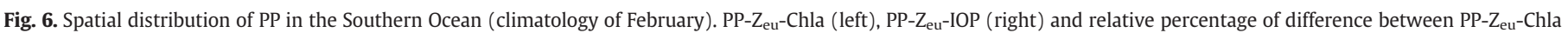
and PP- $\mathrm{Z}_{\mathrm{eu}}-\mathrm{IOP}$ (center). The white pixels correspond to areas with no data.

to note that we used the CHL1 even in waters that hardly fit to the Case 1 assumption, for instance on the Patagonian shelf and around the Antarctic Peninsula (Dierssen \& Smith, 2000; Garcia et al., 2005). The error in $\mathrm{Z}_{\mathrm{eu}}$ induced by the error in Chla depends on the in situ concentrations. A 100\% error in lower Chla values has higher impact on $Z_{\text {eu }}$ than $100 \%$ error in high Chla values. For instance, a $100 \%$ overestimation in the lowest and highest in situ Chla $\left(0.05 \mathrm{mg} / \mathrm{m}^{3}\right.$ and $\left.9.98 \mathrm{mg} / \mathrm{m}^{3}\right)$ of our SeaWiFS validation data set would lead to an error of 26.79 and $2.82 \mathrm{~m}$ in $\mathrm{Z}_{\mathrm{eu}}$, respectively.

\subsection{Zeu spatial distribution}

The spatial distribution maps of $\mathrm{Z}_{\mathrm{eu}}-\mathrm{Chla}$ and $\mathrm{Z}_{\mathrm{eu}}-\mathrm{IOP}$ highlighted large differences in the South Pacific subtropical gyre and south of $60^{\circ} \mathrm{S}$ (Fig. 4). Morel et al. (2007) evaluated the Chla approach for waters of the South Pacific subtropical gyre with data collected during the BIOSOPE cruise and showed that an empirical relationship based on Chla (Morel \& Gentilini, 2004) was valid to estimate $Z_{\text {eu }}$ in those waters. Thus, for this region the satellite $Z_{\mathrm{eu}}$-Chla may be the better choice. Unfortunately, beside the data from the BIOSOPE cruise, there were no in situ measurements of $Z_{\mathrm{eu}}$ available from the South Pacific and other SO subtropical gyres for a detailed investigation. Our comparison between satellite and in situ $Z_{\text {eu }}$ for data south of $60^{\circ} \mathrm{S}$ did not show significant differences between the approaches for SeaWiFS and slightly better estimates of $Z_{\mathrm{eu}}$-Chla for MODIS (see the Appendix for scatterplots, Fig. A5).
Overall, $\mathrm{Z}_{\mathrm{eu}}$-IOP was shallower than $\mathrm{Z}_{\mathrm{eu}}$-Chla, as observed by Lee et al. (2007) for other regions.

Although the spatial distribution of $\mathrm{Z}_{\mathrm{eu}}$ is consistent, it is important to mention that close to the Antarctic continent the values might be impacted by ice contamination. Pixels contaminated by cloud/ice and straylight are flagged in the Level-3 data. Nevertheless, Belanger, Ehn, and Babin (2007) and Wang and Shi (2009) showed that the standard SeaWiFS and MODIS flags may not remove all pixels impacted by the adjacency effect, sub-pixel ice and mixed ice-water contamination. Based on radiative transfer simulations Belanger et al. (2007) showed the significant impact of the adjacency effect and sub-pixel ice contamination on the water leaving radiance and derived Chla and IOP products. In general, the sub-pixel contamination leads to an overestimation of Chla and the total absorption at $443 \mathrm{~nm}\left(a_{443}\right)$. The adjacency effect overestimates Chla in low Chla waters $\left(0.05 \mathrm{mg} \mathrm{m}^{-3}\right)$ and for Chla $>0.5 \mathrm{mg} \mathrm{m}^{-3}, a_{443}$ and Chla retrievals are underestimated. Wang and Shi (2009) observed that MODIS Chla is often overestimated in sea ice contaminated pixels. Therefore, both shallower and deeper $\mathrm{Z}_{\mathrm{eu}}$ regions observed close to the Antarctic continent might be biased.

In addition, when comparing the sensors, the spatial differences were larger close to the sea ice edge and were likely related to the few pixels sampled at different times (Fig. 5). These differences were as large as $20 \%$ and more pronounced in the $\mathrm{Z}_{\mathrm{eu}}-\mathrm{IOP}$, which might be explained by the following reasons. The IOP approach is probably more influenced by the atmospheric correction since the QAA uses the 
$670 \mathrm{~nm}$ band to derive the total absorption at the reference wavelength. The $670 \mathrm{~nm}$ band is important for the retrievals of IOPs from $R_{\mathrm{rs}}$ in high-absorption waters (Lee et al., 2006, 2007). At $670 \mathrm{~nm}$ water absorption dominates and the signal to noise ratio is low, which in turn leads to a high sensitivity to light conditions. This is also the most likely reason for the large differences seen south of $60^{\circ} \mathrm{S}$ (Figs. 4 and 5). Moreover, differences between $Z_{\mathrm{eu}}-\mathrm{SWF}$ and $\mathrm{Z}_{\mathrm{eu}}$-MODIS might be associated to changes in the QAA depending on the sensor used. Examples of the QAA adjustment to sensors are the difference in reference wavelength (555 nm for SeaWiFS and $547 \mathrm{~nm}$ for MODIS) and the constants used to derive total absorption at the reference wavelength. These are based on relations to a different set of collocations and the solar zenith angle. An alternative is the use of merged products (e.g. GlobColour), aimed to reduce discrepancies caused by the use of different sensors as observed here.

\subsection{Validation of $a_{p h}$}

The assessment of MODIS and SeaWiFS QAA-derived $a_{p h}$ is presented in Table 1. The comparison of $R_{\mathrm{rs}}$-satellite and in situ $a_{p h}$ shows satisfactory results in terms of log_MAE for both sensors at 412 and $443 \mathrm{~nm}$, and at 488 and 531 for MODIS. The percentage differences are higher than the values presented by Lee et al. (2011). Nevertheless, Lee et al. (2011) derived $a_{p h}$ from ship borne $R_{\mathrm{rs}}$ instead of satellite $R_{\mathrm{rs}}$; larger uncertainties would be expected in satellite $R_{\mathrm{rs}}$. The $E$ of $a_{p h}$-MODIS at 412, 443 and 488 were higher than the values reported by Shang, Dong, et al. (2011) when evaluating QAA-derived $a_{p h}$ from satellite MODIS $R_{\mathrm{rs}}$ in the Taiwan Strait as well. Generally, $a_{p h}$-MODIS showed lower log_bias and log_MAE (except at $555 \mathrm{~nm}$ ) than $a_{p h}$-SWF for the same wavelengths. Further, the comparison of log_MAE from the Chla and $a_{p h} 443$ validations suggested improvement of $a_{p h} 443$ over Chla in the SO for MODIS, as observed by Shang, Dong, et al. (2011) in the Taiwan Strait. Thus, MODIS should be preferred in PP models based on $a_{p h}$ that use either $a_{p h} 443$ or $\bar{a}_{p h}$.

Uncertainties in the satellite $a_{p h}$ could be introduced by error in the in situ measurements of $a_{p h}$, as well as in the satellite $R_{\mathrm{rs}}$ and in the estimation of gelbstoff absorption by the QAA (Lee et al., 2006, 2011, Shang, Dong, et al., 2011). Unfortunately, it is out of the scope of this paper to propose modifications in the algorithm for the SO. Hirawake et al. (2011) modified the QAA based on underwater spectral radiation data and in situ $a_{p h}$ from the Indian Sector of the SO. This modified QAA was also tested by us, but the results were less robust than with the original QAA (results not shown). In part, regional differences across the SO, as discussed above and as seen in the $Z_{\text {eu }}$, make it difficult to extrapolate local properties to the entire region.

Because $\mathrm{Z}_{\mathrm{eu}}$-IOP was calculated using the same approach as $a_{p h} 490$ (488), we could also expect an improvement of Zeu-IOP over Zeu-Chla; particularly for MODIS that showed a larger difference between the two $Z_{\text {eu }}$ approaches. However, this was not observed here and it is likely related to our validation data sets of $Z_{\text {eu }}$ and $a_{p h}$, which greatly differ in number of samples and location. Moreover, our $a_{p h}$ validation data set is small, especially for SeaWiFS. From 271 in situ $a_{p h}$ collected between 2007 and 2010, 13 matched with SeaWiFS observations. Persistent cloudiness and high solar zenith angles limit the satellite retrievals in the SO.

\subsection{Primary production}

Finally, the impact of the $\mathrm{Z}_{\text {eu }}$ products on the PP was as expected; deeper $Z_{\text {eu }}$ led to an increase in PP as more light was available (Fig. 6). Note that the classification of empirical and semi-analytical used for $\mathrm{Z}_{\mathrm{eu}}$ is not valid for PP since both PP- $\mathrm{Z}_{\mathrm{eu}}-$ Chla and PP- $\mathrm{Z}_{\mathrm{eu}}-\mathrm{IOP}$ used $a_{p h}$ derived from QAA. The spatial differences observed between $Z_{\mathrm{eu}}-\mathrm{Chla}$ and $Z_{\mathrm{eu}}-\mathrm{IOP}$ strongly influenced the PP estimation. In both PP calculations we used the same set of input data (PAR, $\mathrm{D}_{\text {irr }}, \bar{a}_{p h}$ ), except for $Z_{\text {eu, }}$, thus the observed differences can be directly attributed to $Z_{\text {eu. }}$. In particular, $\mathrm{PP}-\mathrm{Z}_{\mathrm{eu}}-$ Chla estimates were much higher than PP- $\mathrm{Z}_{\mathrm{eu}}-\mathrm{IOP}$ in the west part of the South Pacific subtropical gyre and south of $60^{\circ} \mathrm{S}$. The latter region is of great importance in the global carbon cycle, as pointed out by Arrigo, van Dijken, and Long (2008) and Takahashi et al. (2009). According to these authors, once the sea ice retreats in springtime, more light and nutrients become available enhancing the development of phytoplankton blooms and leading to a strong sink of atmospheric $\mathrm{CO}_{2}$. Accurate estimates of PP are essential for a better understanding of the role of the $\mathrm{SO}$ in the global carbon cycle.

From the results presented here it becomes clear that the uncertainties of $Z_{\mathrm{eu}}$ should be considered to improve the estimates of PP. Saba et al. (2011) investigated how satellite derived sea surface temperature, mixed layer depth, Chla and PAR affected the PP estimates of 21 ocean colour models. They found that when uncertainties of the Chla are accounted for in PP models, the root mean square difference is reduced by $44 \%$ in the Antarctic Polar Front Zone. They also observed that biases in the ocean colour PP estimates are related to the water column depth, possibly due to uncertainties in the $\mathrm{Z}_{\mathrm{eu}}$.

\section{Summary and conclusions}

This paper provides the first quality assessment of the $Z_{\text {eu }}$ and $a_{p h}$ products of MODIS and SeaWiFS using a large data set of in situ measurements in the SO. In summary, satellite $Z_{\text {eu }}$ derived using the Chla and IOP approaches are reliable in the SO. Although uncertainties depend on the sensor and approach used, the best results were obtained by the IOP approach and SeaWiFS data. Within the MODIS data, $Z_{\text {eu }}$ estimation with the Chla approach generally yielded better results than the IOP approach. When assessing the differences in the spatial distribution between $\mathrm{Z}_{\mathrm{eu}}-\mathrm{Chla}$ and $\mathrm{Z}_{\mathrm{eu}}-\mathrm{IOP}$, large discrepancies were observed over specific regions with significant impact on the PP retrievals. Those differences were not observed in the validation. Therefore, we emphasize the importance of spatial studies together with the validation using in situ measurements for comparing ocean colour satellite products retrieved from different sensors and approaches. In addition, temporal differences should also be accounted for. Further, we validated $a_{p h}$ and found that MODIS data lead to lower uncertainties of $\bar{a}_{p h}$ and $a_{p h} 443$ than SeaWiFS data. Thus, MODIS should be preferred in PP models based on $a_{p h}$ in the SO.

Our validation showed that the best satellite retrievals of Zeu and $\bar{a}_{p h}$ in the SO are not from the same sensor. To which extend these results are influenced by the lack of in situ measurements in our data set and/or by regional differences in the SO is still unclear. To look more deeply in this issue and to address these differences found in the spatial distribution of $Z_{\text {eu }}$ and PP, a more representative data set of simultaneous bio-optical and PP data is necessary. The results presented here can support future campaigns by prioritizing areas of disagreement between approaches and poorly sampled regions to reduce uncertainty of PP in regional and global scales. In addition, special designed satellite missions using at least two quasi-polar orbits and same optical sensor could be considered. In this case, earlier (later) equator crossing time in descending (ascending) mode would increase signal to noise for the SO, thus reducing uncertainties of PP estimates.

\section{Acknowledgements}

We thank the Ocean Biology Processing Group of NASA for the distribution of the SeaWiFS and MODIS data. Thanks are also due to the Australian Antarctic Data Centre, LEFE-CYBER and PROOF program, SeaWiFS Bio-optical Archive and Storage System, United States JGOFS Data Server and Palmer Long-Term Ecological Research (LTER) for the public access to the in situ data. Data from the Palmer LTER data archive were supported by Office of Polar Programs, NSF 
Grants OPP-9011927, OPP-9632763 and OPP-0217282. We are grateful to the many providers of the in situ data and Brenner Silva and Marc Taylor for discussions. We thank Christian Wolf and Wee Cheah for the sampling of absorption data during ANT-XXVI/3 and ANT-XXVIII/3, respectively, Sonja Wiegmann and Marta Kaspar for the analysis of these data and the principal scientists, crew and other scientists and students for the support during these two RV

\section{Appendix A}

Table A1

List of cruises.

\begin{tabular}{|c|c|c|c|}
\hline Database & Cruise & Variables & Year \\
\hline $\mathrm{AADC}^{\mathrm{a}}$ & Broke-West & Chla, $\mathrm{Z}_{\mathrm{eu}}$ & 2006 \\
\hline AADC & SAZ-Sense Voyage & Chla, $\mathrm{Z}_{\mathrm{eu}}$ & 2007 \\
\hline $\mathrm{JGFOS}^{\mathrm{b}}$ & Nbp97_8 & $Z_{\text {eu }}$ & 1997 \\
\hline LEFE-CYBER ${ }^{\mathrm{C}}$ & Biosope & Chla, $Z_{\text {eu }}$ & 2004 \\
\hline PAL Ter ${ }^{\mathrm{d}}$ & $\begin{array}{l}\text { PAL9798, PAL9899, LMG98-01, PAL9900, LMG99-01, LMG03-01, } \\
\text { LMG05-01, PAL0607, LMG08-01 }\end{array}$ & Chla, $\mathrm{Z}_{\mathrm{eu}}$ & $1998,1999,2003,2003,2006,2008$ \\
\hline SeaBASS e & nbp97__ $1^{\mathrm{f}}$, rev98__1 $1^{\mathrm{f}}$, rev98_2 $2^{\mathrm{f}}$ & $Z_{\text {eu }}$ & 1997, 1998 \\
\hline SeaBASS & AMT 5, AMT6, AMT 6B, AMT 7, AMT 8 & Chla, $\mathrm{Z}_{\mathrm{eu}}$ & 1997, 1998, 1999 \\
\hline SeaBASS & ROAVERRS $^{f}$ & $\mathrm{Z}_{\text {eu }}$ & 1997,1998 \\
\hline SeaBASS & Indoex ${ }^{\mathrm{f}}$ & $\mathrm{Z}_{\mathrm{eu}}$ & 1999 \\
\hline SeaBASS & AMLR $^{\mathrm{f}}$ & $\mathrm{Z}_{\mathrm{eu}}$ & $2001,2002,2004,2006,2007,2008$ \\
\hline SeaBASS & $\mathrm{LMG0402}^{\mathrm{f}}$ & Chla, $Z_{\mathrm{eu}}$ & 2004 \\
\hline SeaBASS & Bencal02 & Chla, $\mathrm{Z}_{\mathrm{eu}}$ & 2002 \\
\hline SeaBASS & NBP0606 ${ }^{f}$ & Chla, $Z_{\text {eu }}$ & 2006 \\
\hline SeaBASS & i06s & Chla, $Z_{\text {eu }}$ & 2008 \\
\hline SeaBASS & SO_GASEX & $a_{p h}$ & 2008 \\
\hline SeaBASS & CLIVAR_p18 & $a_{p h}$ & 2008 \\
\hline SeaBASS & CLIVAR_i8si9n & $a_{p h}$ & 2007 \\
\hline Own data set & ANT-XXVI/3 & $a_{p h}$ & 2010 \\
\hline Own data set & ANT-XXVIII/3 & $a_{p h}$ & 2012 \\
\hline
\end{tabular}

a Australian Antarctic Data Centre.

b United States JGOFS Data Server.

c http://www.obs-vlfr.fr/proof/index_vt.htm, French PROOF program.

d Palmer Long-Term Ecological Research (LTER).

e SeaWiFS Bio-optical Archive and Storage System (SeaBASS), Werdell et al. (2003).

${ }^{\mathrm{f}} \mathrm{Z}_{\mathrm{eu}}$ calculated by the authors from vertical profiles of PAR.

a)
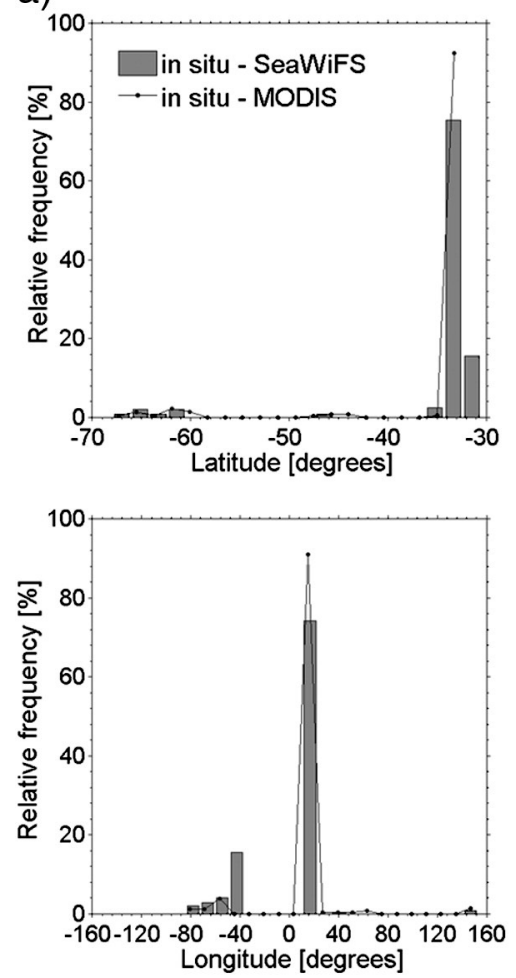

b)
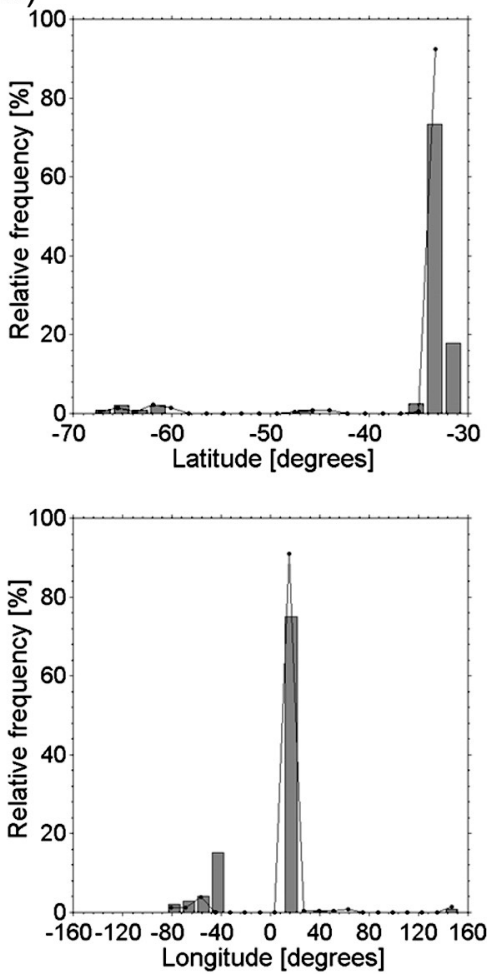

Polarstern cruises. We also thank the two anonymous reviewers whose comments helped to improve the manuscript. The present work was conducted within the framework of the Helmholtz-University Young Investigators Group PHYTOOPTICS in cooperation with the Institute of Environmental Physics (University of Bremen) and Alfred Wegener Institute. The first author is supported by CAPES, Brazil, by the research grant BEX 3483/09-6. 


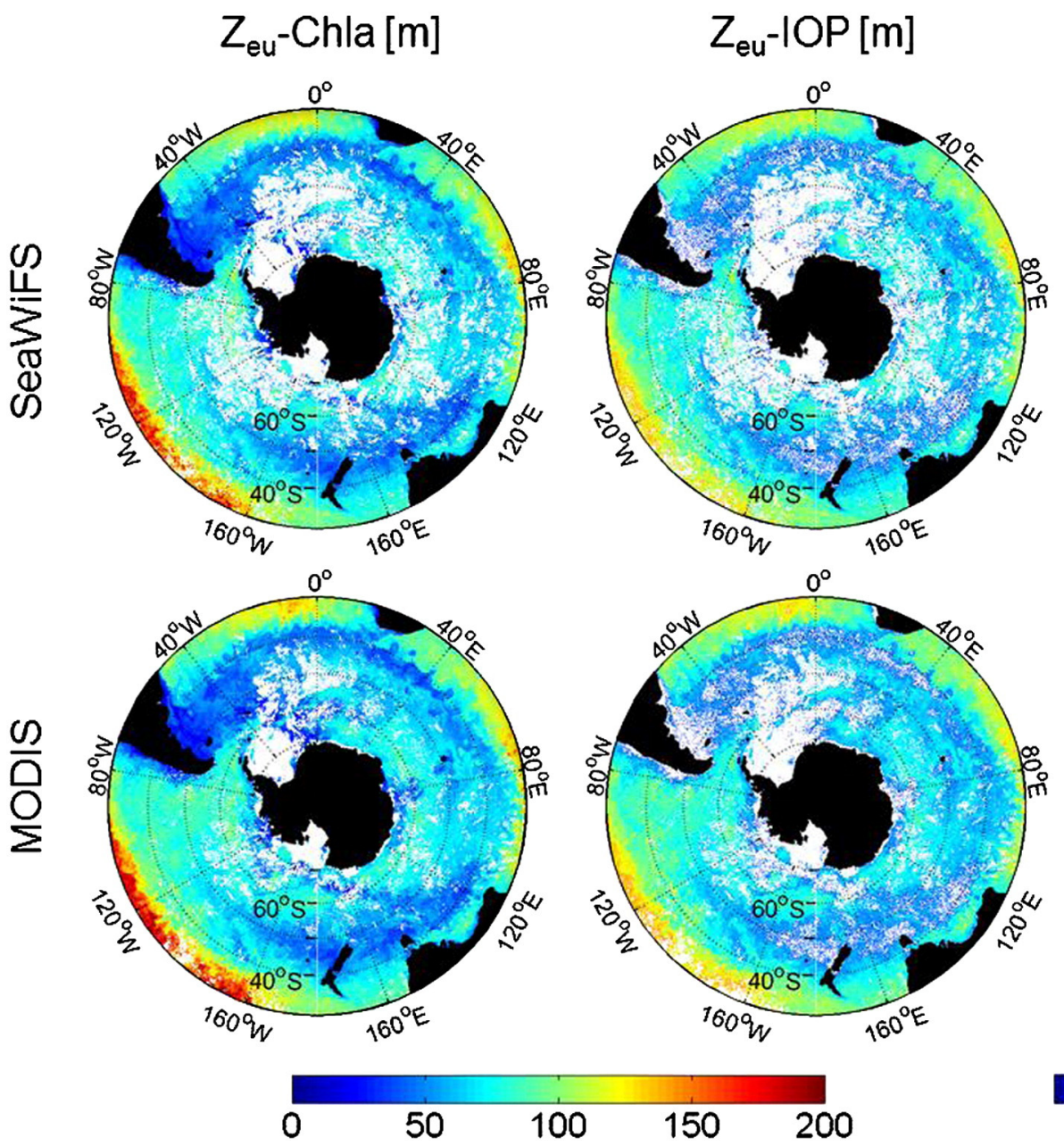

\section{$\mathrm{Z}_{\mathrm{eu}}$ Difference (\%)}
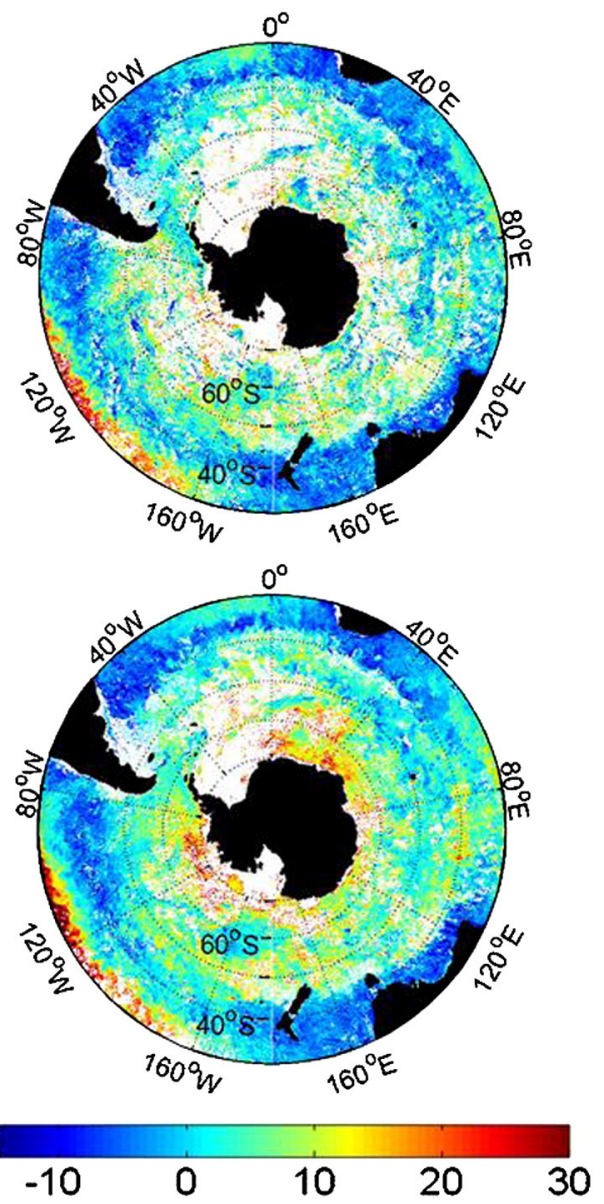

Fig. A2. Spatial distribution of $\mathrm{Z}_{\mathrm{eu}}$ in the Southern Ocean in February, 2003. The white pixels correspond to areas with no data.

\section{$\mathrm{Z}_{\text {eu}}{ }^{-}$-Chla - Difference [\%] $\quad Z_{\text {eu}}-1 O P$ - Difference [\%]}
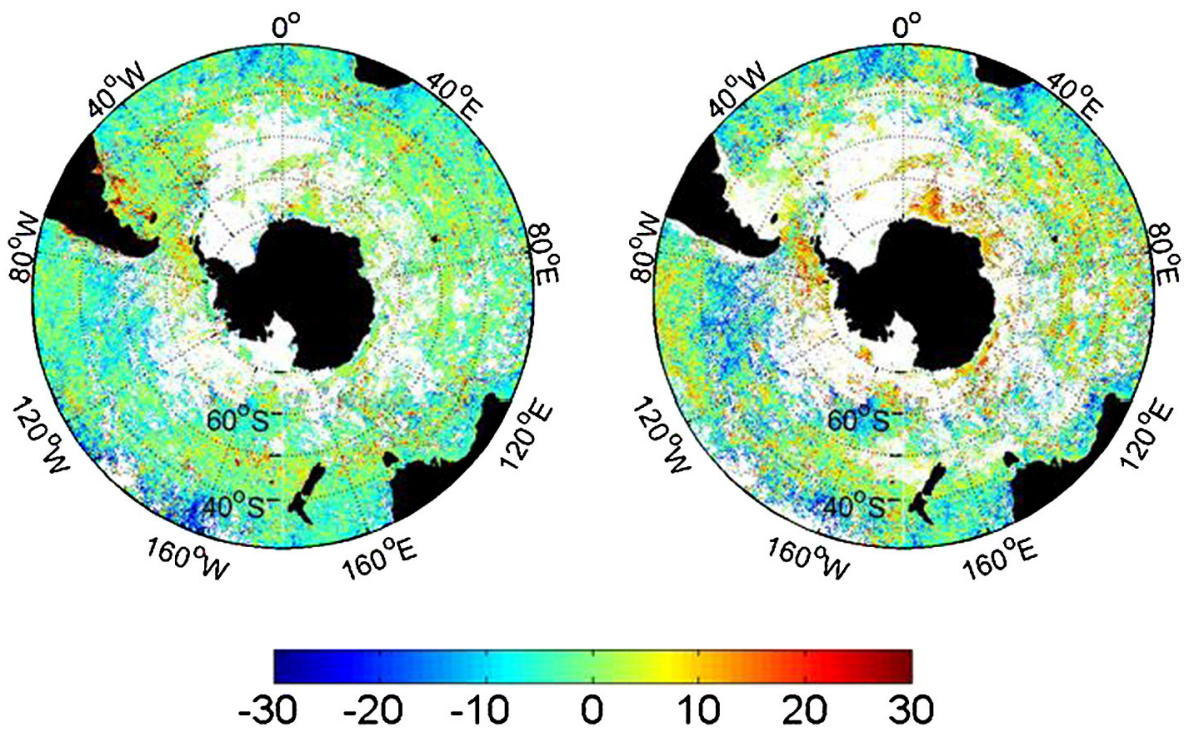

Fig. A3. Spatial distribution of the relative percentage of difference between SeaWiFS and MODIS for February, 2003. The white pixels correspond to areas with no data. 

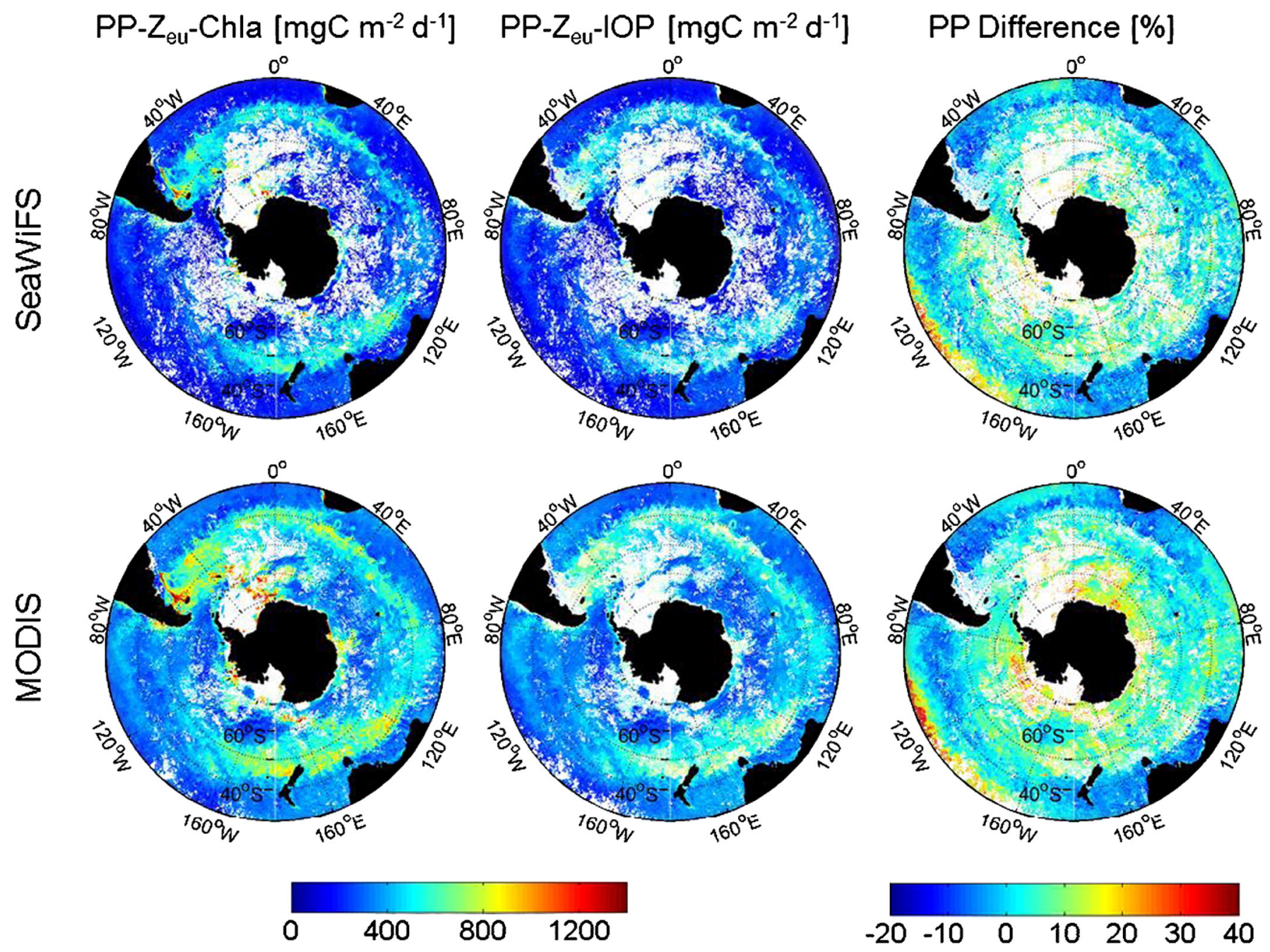

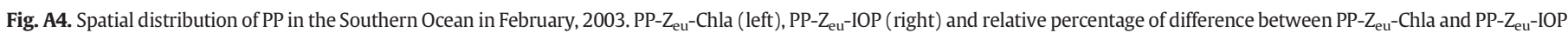
(center). The white pixels correspond to areas with no data. 

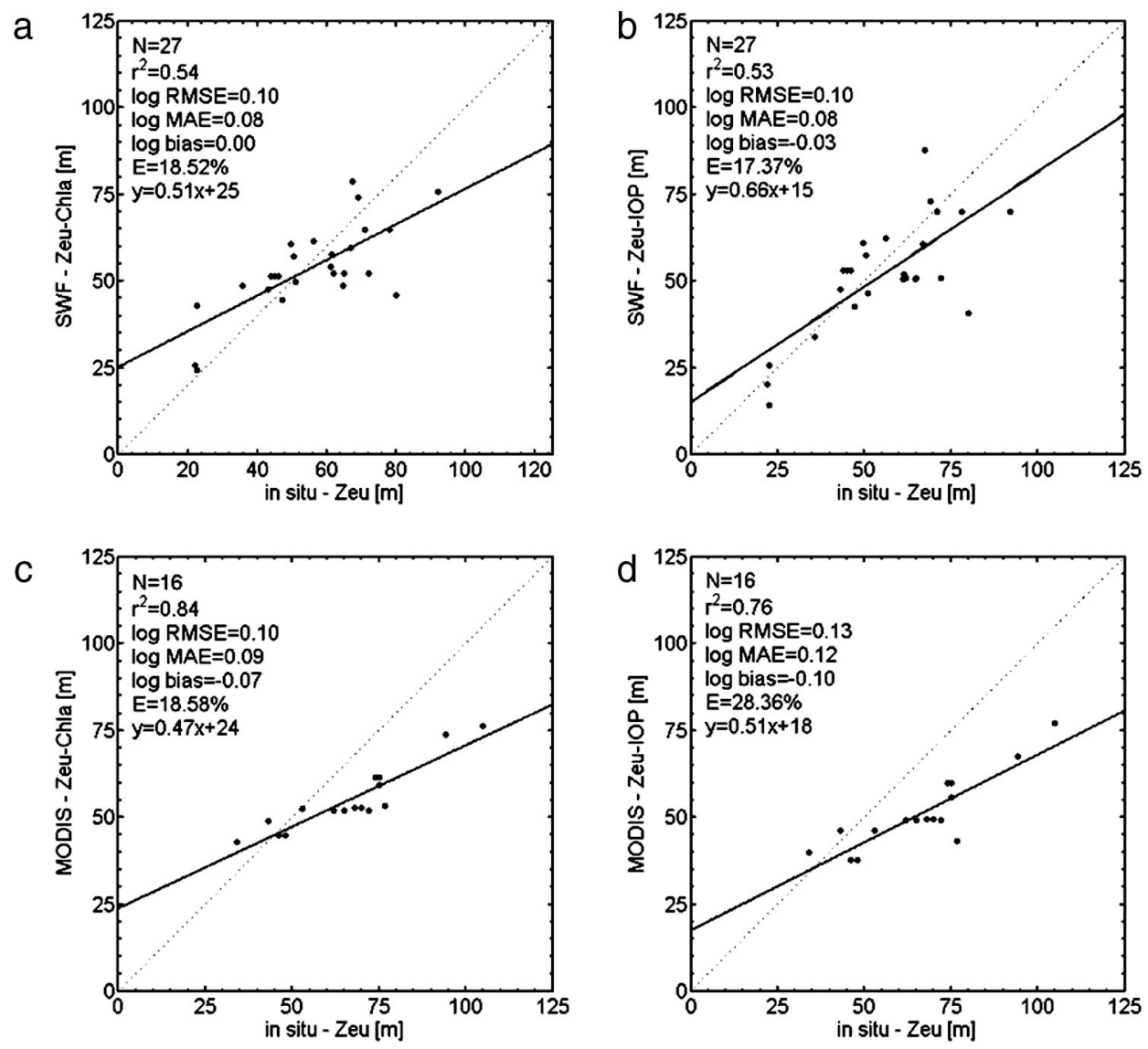

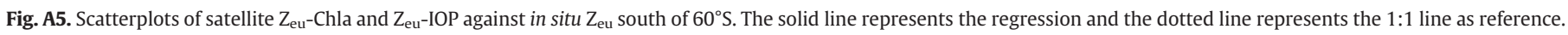

\section{References}

Arrigo, K. R., van Dijken, G., \& Long, M. (2008). Coastal Southern Ocean: a strong anthropogenic $\mathrm{CO}_{2}$ sink. Geophysical Research Letters, 35, L21602.

Behrenfeld, M. J., \& Falkowski, P. G. (1997). Photosynthetic rates derived from satellite-based chlorophyll concentration. Limnology and Oceanography, 42, 1-20.

Belanger, S., Ehn, J. K., \& Babin, M. (2007). Impact of sea ice on the retrieval of water-leaving reflectance, chlorophyll a concentration and inherent optical properties from satellite ocean color data. Remote Sensing of Environment, 111, 51-68.

Campbell, J., Antoine, D., Armstrong, R., Arrigo, K., Balch, W., Barber, R., et al. (2002). Comparison of algorithms for estimating ocean primary production from surface chlorophyll, temperature, and irradiance. Global Biogeochemical Cycles, 16, 1035.

Carr, M. -E., Friedrichs, M. A. M., Schmeltz, M., Noguchi Aita, M., Antoine, D., Arrigo, K. R., et al. (2006). A comparison of global estimates of marine primary production from ocean color. Deep Sea Research Part II: Topical Studies in Oceanography, 53, 741-770.

Dierssen, H., \& Smith, R. (2000). Bio-optical properties and remote sensing ocean color algorithms for Antarctic Peninsula waters. Journal of Geophysical Research, 105 26.301-26.312.

Falkowski, P. G., \& Raven, J. A. (2007). Aquatic Photosynthesis (2nd ed.)Princeton: Princeton University Press.

Feldman, G. C., \& McClain, C. R. (October 27). Ocean Color Chlorophyll (OC) v6, Ocean Color WebOcean Color Chlorophyll (OC) v6, Ocean Color Web. In N. Kuring, S. W. Bailey, B. F. Franz, G. Meister, P. J. Werdell, \& R. E. Eplee (Eds.), : NASA Goddard Space Flight Center (12 December 2012. http://oceancolor.gsfc.nasa.gov/REPROCESSING/ R2009/ocv6/).

Garcia, C. A. E., Garcia, V. M. T., \& McClain, C. R. (2005). Evaluation of SeaWiFS chlorophyll algorithms in the Southwestern Atlantic and Southern Oceans. Remote Sensing of Environment, 95, 125-137.

Hirawake, T., Shinmyo, K., Fujiwara, A., \& Saitoh, S. I. (2012). Satellite remote sensing of primary productivity in the Bering and Chukchi Seas using an absorption-based approach. ICES Journal of Marine Science, 69, 1194-1204.

Hirawake, T., Takao, S., Horimoto, N., Ishimaru, T., Yamaguchi, Y., \& Fukuchi, M. (2011). A phytoplankton absorption-based primary productivity model for remote sensing in the Southern Ocean. Polar Biology, 34, 291-302.

Kahru, M., \& Mitchell, B. G. (2010). Blending of ocean colour algorithms applied to the Southern Ocean. Remote Sensing Letters, 1, 119-124.

Kirk, J. T. O. (2011). Light and photosynthesis in aquatic ecosystems (3rd ed.)Cambridge: Cambridge University Press.
Lee, Z., Arnone, R., Hu, C., Werdell, P. J., \& Lubac, B. (2010). Uncertainties of optical parameters and their propagations in an analytical ocean color inversion algorithm. Applied Optics, 49, 369-381.

Lee, Z., Carder, K., \& Arnone, R. (2006). The quasi-analytical algorithm. In Z. Lee (Ed.), Remote Sensing of Inherent Optical Properties: Fundamentals, Tests of Algorithms, and Applications (pp. 73-79). Dartmouth: International Ocean-Colour Coordinating Group.

Lee, Z., Du, K., Arnone, R., Liew, A., \& Penta, B. (2005). Penetration of solar radiation in the upper ocean: a numerical model for oceanic and coastal waters. Journal of Geophysical Research, 110, C09019.

Lee, Z., Lance, V. P., Shang, S., Vaillancourt, R., Freeman, S., Lubac, B., et al. (2011). An assessment of optical properties and primary production derived from remote sensing in the Southern Ocean (SO GasEx). Journal of Geophysical Research, 116, C00F03.

Lee, Z., Lubac, B., Werdell, J., \& Arnone, R. (2009). An update of the quasi-analytical algorithm (QAA-v5), open file rep. available at: http://www.ioccg.org/groups/Software OCA/QAA_v5.pdf (9 pp., (last access: 5 November 2012)).

Lee, Z., Weidemann, A., Kindle, J., Arnone, R., Carder, K. L., \& Davis, C. (2007). Euphotic zone depth: Its derivation and implication to ocean-color remote sensing. Journal of Geophysical Research, 112, C03009.

Marrari, M., Hu, C., \& Daly, K. (2006). Validation of SeaWiFS chlorophyll a concentrations in the Southern Ocean: A revisit. Remote Sensing of Environment, 105, 367-375.

Mélin, F. (2011). Comparison of SeaWiFS and MODIS time series of inherent optical properties for the Adriatic Sea. Ocean Science, 7, 351-361.

Morel, A., \& Berthon, J. F. (1989). Surface pigments, algal biomass profiles, and potential production of the euphotic layer: relationships reinvestigated in view of remote-sensing applications. Limnology and Oceanography, 34, 1545-1562.

Morel, A., Claustre, H., Antoine, D., \& Gentili, B. (2007). Natural variability of bio-optical properties in Case 1 waters: attenuation and reflectance within the visible and near-UV spectral domains, as observed in South Pacific and Mediterranean waters. Biogeosciences, 4, 913-925.

Morel, A., \& Gentilini, B. (2004). Radiation transport within oceanic (case 1) water Journal of Geophysical Research: Oceans, 109 C06008.

O'Reilly, J. E., Maritorena, S., Siegel, D. A., O'Brien, M. C., Toole, D., Mitchell, B. G., et al. (2000). Ocean color chlorophyll algorithms for SeaWiFS, OC2, and OC4: Version 4. In S. B. Hooker, \& E. R. Firestone (Eds.), SeaWiFS Postlaunch Calibration and Validation Analyses, Part 3 (pp. 9-23). Maryland: NASA Goddard Space Flight Center.

Saba, V. S., Friedrichs, M. A. M., Antoine, D., Armstrong, R. A., Asanuma, I., Behrenfeld, M. J., et al. (2011). An evaluation of ocean color model estimates of marine primary productivity in coastal and pelagic regions across the globe. Biogeosciences, 8 489-503. 
Shang, S., Dong, Q., Lee, Z., Li, Y., \& Behrenfeld, M. (2011). MODIS observed phytoplankton dynamics in the Taiwan Strait. Biogeosciences, 8, 841-850.

Shang, S., Lee, Z., \& Wei, G. (2011). Characterization of MODIS-derived euphotic zone depth: results for the China Sea. Remote Sensing of Environment, 115, $180-186$.

Szeto, M., Werdell, P. J., Moore, T. S., \& Campbell, J. W. (2011). Are the world's oceans optically different? Journal of Geophysical Research, 116, C0OH04.

Takahashi, T., Sutherland, S. C., Wanninkhof, R., Sweeney, C., Feely, R. A., Chipman, D. W. et al. (2009). Climatological mean and decadal change in surface ocean pCO2, and net sea-air CO2 flux over the global oceans. Deep Sea Research Part II: Topical Studies in Oceanography, 56, 554-577.

Taylor, B. B., Torrecilla, E., Bernhardt, A., Taylor, M. H., Peeken, I., Röttgers, R., et al. (2011). Bio-optical provinces in the eastern Atlantic Ocean and their biogeographical relevance. Biogeosciences, 8, 3609-3629.
Thomalla, S. J., Fauchereau, N., Swart, S., \& Monteiro, P. M. S. (2011). Regional scale characteristics of the seasonal cycle of chlorophyll in the Southern Ocean. Biogeosciences, 8, 2849-2866.

Wang, M. H., \& Shi, Wei (2009). Detection of ice and mixed ice-water pixels for MODIS ocean color data processing. IEEE Transactions on Geoscience and Remote Sensing, 47, 2510-2518.

Werdell, P. J., Bailey, S. W., Fargion, G. S., Pietras, C., Knobelspiesse, K. D., Feldman, G. C., et al. (2003). Unique data repository facilitates ocean color satellite validation. Eos, Transactions of the American Geophysical Union, 84, 377.

Willmott, C. J., \& Matsuura, K. (2005). Advantages of the mean absolute error (MAE) over the root mean square error (RMSE) in assessing average model performance. Climate Research, 30, 79-82.

Zibordi, G., Melin, F., \& Berthon, J. -F. (2006). Comparison of SeaWiFS, MODIS and MERIS radiometric products at a coastal site. Geophysical Research Letters, 33, L06617. 